\title{
Diffuse and Pulsating Aurora
}

Yukitoshi Nishimura, Marc R. Lessard, Yuto Katoh, Yoshizumi Miyoshi, Eric Grono, Noora Partamies, Nithin Sivadas, Keisuke Hosokawa, Mizuki Fukizawa, Marilia Samara, Robert G. Michell, Ryuho Kataoka, Takeshi Sakanoi, Daniel K. Whiter, Shinichiro Oyama, Yasunobu Ogawa, Satoshi Kurita

\section{Y. Nishimura}

Department of Electrical and Computer Engineering and Center for Space Physics, Boston University, Boston, MA, USA

+1-617-353-5990, toshi16@bu.edu

\section{R. Lessard}

Space Science Center, University of New Hampshire, Durham, NH USA

603-862-2590,marc.lessard@unh.edu

\section{Y. Katoh}

Department of Geophysics, Graduate School of Science, Tohoku University, Sendai, Japan

+81-22-795-6516, yuto@ @stpp.gp.tohoku.ac.jp

Y. Miyoshi

Institute for Space Earth Environmental Research, Nagoya University, Nagoya, Japan

+81-52-747-6340, miyoshi@isee.nagoya-u.jp

E. Grono

Department of Physics and Astronomy, University of Calgary, Calgary, Alberta, Canada

+1-403-220-5385, emgrono@ucalgary.ca

N. Partamies

Department of Arctic Geophysics, The University Centre in Svalbard, Longyearbyen, Norway

Birkeland Centre for Space Science, Norway

+47-7902-6441, noora.partamies@unis.co

N. Sivadas

Department of Electrical and Computer Engineering and Center for Space Physics, Boston University, Boston, MA, USA

617-961-2670,nithin@bu.edu

K. Hosokawa

Department of Communication Engineering and Informatics, University of Electro-Communications, Tokyo, Japan

+81-42-443-5299, keisuke.hosokawa@uec.ac.jp 


\section{Fukizawa}

Department of Geophysics, Graduate School of Science, Tohoku University, Sendai, Japan

+81-22-795-6737, fukizawa.m@pparc.gp.tohoku.ac.jp

\section{Samara}

NASA Goddard Space Flight Center, Greenbelt, MD, USA

301-286-2813, marilia.samara@ nasa.gov

R. G. Michell

Department of Astronomy, University of Maryland, College Park, MD, USA

NASA Goddard Space Flight Center, Greenbelt, MD, USA

301-286-5959, robert.g.michell@nasa.gov

\section{R. Kataoka}

National Institute of Polar Research (NIPR), Tachikawa, Japan

SOKENDAI, Tachikawa, Japan

+81-042-512-0929, kataoka.ryuho@nipr.ac.jp

\section{T. Sakanoi}

Department of Geophysics, Graduate School of Science, Tohoku University, Sendai, Japan

+81-022-795-6609, tsakanoi@pparc.gp.tohoku.ac.jp

D. K. Whiter

Department of Physics and Astronomy, University of Southampton, Southampton, $U K$

+44-23-8059-2095, d.whiter@ soton.ac.uk

S. Oyama

Institute for Space Earth Environmental Research, Nagoya University, Nagoya, Japan

+81-52-789-4308, soyama@isee.nagoya-u.ac.jp

Y. Ogawa

National Institute of Polar Research, Tokyo, Japan

+81-42-512-0664, yogawa@nipr.ac.jp

\section{S. Kurita}

Institute for Space Earth Environmental Research, Nagoya University, Nagoya, Japan

+81-52-747-6306, kurita@isee.nagoya-u.ac.jp

Abstract. This chapter reviews fundamental properties and recent advances of diffuse and pulsating aurora. Diffuse and pulsating aurora often occurs on closed field lines and involves energetic electron precipitation by wave-particle interaction. After summarizing the definition, 
large-scale morphology, types of pulsation, and driving processes, we review observation techniques, occurrence, duration, altitude, evolution, small-scale structures, fast modulation, relation to high-energy precipitation, the role of ECH waves, reflected and secondary electrons, ionosphere dynamics, and simulation of wave-particle interaction. Finally we discuss open questions of diffuse and pulsating aurora.

Keywords. Pulsating aurora; diffuse aurora; wave-particle interaction; whistlermode chorus; energetic electron precipitation 


\section{Introduction}

This chapter reviews diffuse aurora, with a particular emphasis on recent advances in pulsating aurora in the past 20 years. Section 1.1 describes definition and basic properties. Section 1.2 reviews a historical context of pulsating aurora. Section 2 describes recent observations of pulsating aurora over the past 20 years, including measurement techniques (Section 2.1) and observational findings (Section 2.2). Section 3 states recent advances in simulation. Section 4 briefly summarizes those findings and discusses open questions.

\subsection{Definition and Basic Properties}

Diffuse aurora is caused by precipitation from the plasma sheet without additional acceleration in the low-altitude magnetosphere. Unlike discrete or Alfvenic aurora, diffuse aurora is a region of glow without large-scale structures (Lui et al., 1973) and does not form rays or show shear or rotational motion (Yamamoto, 1988). Pulsating aurora is a type of diffuse aurora that appears as irregular patches with quasi-periodic on-off switching of its intensity. The horizontal size and periodicity are typically $\sim 10-200 \mathrm{~km}$ of $\sim 2-20 \mathrm{~s}$ (Royrvik and Davis, 1977; Yamamoto, 1988). Auroral intensity modulation of a similar size and period can also occur over discrete aurora but such modulation is not included in this definition.

Pulsating aurora is dominated by the green color at $557.7 \mathrm{~nm}$ wavelength. The intensity is somewhat dimmer than typical discrete aurora but is visible in human eyes as blinking patches over the sky (some hundreds of $\mathrm{R}$ up to tens of $\mathrm{kR}$ at 557.7 $\mathrm{nm}$; a few hundred $\mathrm{R}$ to $\sim 10 \mathrm{kR}$ at $427.8 \mathrm{~nm}$ ) (McEwen et al., 1981). The intensity modulation relative to background ranges over $\sim 50-100 \%$.

The emission and ionization occurs in the lower E-region ionosphere at $\sim 90$ 107 km (Stenbaek-Nielsen and Hallinan, 1979; Kataoka et al., 2016; Jones et al., 2009). The vertical extent of pulsating aurora is a few to a few tens of $\mathrm{km}$. The altitude is nearly constant during individual pulses but gradually increases with MLT (Stenbaek-Nielsen and Hallinan, 1979).

Early research associated with pulsating aurora is described in detail by Lessard (2013) and goes as far back as Størmer (1955) and references therein. Although a limited number of publications on pulsating aurora appeared in the literature during these times, interest in the topic increased, somewhat, during the International Geophysical Year (1957/58) and then significantly with a joint Canadian/Japanese Pulsating Aurora Campaign in Saskatchewan in 1980 (McEwen and Duncan, 1981). Throughout the period between that campaign and the last decade, research on pulsating aurora continued at a steady, though perhaps reduced, rate. However, community interest in the topic has grown recently and has resulted in significant strides in our understanding of the process.

\section{Large-scale morphology}

A connection between pulsating aurora and magnetospheric substorms was described long ago, by Akasofu (1968). During a substorm expansion phase, bright 
and dynamic arcs race poleward. Those arcs are typically driven by quasi-static or Alfvenic acceleration of electrons. Following this activity, aurora is characterized by the presence of dim, diffuse auroral patches. After a period of perhaps 10-20 minutes, these patches can appear to pulsate and continue to pulsate for several 10s of minutes or more. Figure 1 shows a typical pulsating aurora event during a substorm. Pulsating aurora starts 10-30 min after substorm poleward expansion and lasts throughout the rest of the substorm. The overall activity typically lasts for 1.5 hour, while events can last for many hours for long-lasting enhanced geomagnetic activity (Jones et al., 2011, 2013). Pulsating aurora occupies the equatorward portion of the auroral oval (also illustrated in Figure 2), and the occurrence region expands with geomagnetic activity. For weak geomagnetic activity ( $\mathrm{Kp}<\sim 2$ ), pulsating aurora is localized to the midnight-dawn sector at $\sim 65-70$ deg latitude. Pulsating aurora extends to the dayside for moderate activity and to lower latitudes $(\mathrm{Kp} \sim 3)$, and can be seen at all local times at more active conditions (Oguti et al., 1981a; Royrvik and Davis, 1977).

The poleward portion of the auroral oval is dominated by discrete aurora (Figures 1-2). Transient auroral brightenings along the poleward boundary of the substorm surge (poleward boundary intensifications or PBIs) occur repetitively and propagate equatorward (streamers). Once the streamers reach the equatorward portion of the auroral oval, pulsating aurora intensifies and its occurrence region extends poleward. At post-midnight, this interaction can be seen as polewardstretching torch-like structures or Omega bands containing pulsating patches that emerge at the poleward boundary of the diffuse auroral region (Oguti et al., 1981b; Sato et al., 2015), often followed by streamers (Henderson, 2012).

The whole pattern of pulsating aurora at post-midnight drifts eastward with a speed of a few hundred meters/sec up to a few $\mathrm{km} / \mathrm{s}$ and extends toward the dayside. The drift is dawnward after midnight and duskward before midnight (Nakamura and Oguti, 1987). The patch drift speed has been reported to follow the $E \times B$ drift speed (Yang et al., 2015). The westward drift before midnight suggests that pulsating auroral structures are determined by distribution of cold plasma in the magnetosphere rather than by eastward magnetic drift of energetic electrons. However, some types of pulsating aurora, such as the streaming and propagating types (see below), propagate much faster than a typical convection speed. This suggests that convection of cold plasma is not the only process that controls pulsating aurora dynamics. Some patches indeed do not follow the $E \times B$ drift speed (Grono et al., 2017, Grono and Donovan, 2018; Humberset et al., 2018).

\section{Types of pulsation}

Each patch generally shows a series of pulsations that typically lasts for several minutes, and the pulse amplitude and shape stay constant for the duration (Yamamoto, 1988; Humberset et al., 2018). Pulsation of each patch is incoherent with neighboring patches; the pulsation period and phase of a patch are independent of those at other patches (Scourfield et al., 1972). Pulsating aurora can also co-exist with non-pulsating diffuse auroral patches (Shiokawa et al., 2014; Grono and Donovan, 2018).

Pulsating aurora has various types of the spatial structure of intensity modulation. Commonly known types are (1) pure pulsation: pulsation at a fixed size and shape, (2) expansion: pulsation expanding from a core and receding back, (3) streaming: a patch moving away from its original position usually along diffuse 
auroral boundaries including Omega band (at tens of $\mathrm{km} / \mathrm{s}$ ), (4) propagating: recurrent waves synchronous over hundreds of $\mathrm{km}$ in size sweeping north-south (at $\sim 10 \mathrm{~km} / \mathrm{s}$ ), (5) flaming (field-aligned motion), (6) flashing ( $\sim 0.2-0.5 \mathrm{~s}$ rapid pulsation, including $3-\mathrm{Hz}$ modulation), and (7) flooding (east-west elongated patches equatorward of streaming patches, moving in east-west) (Oguti et al., 1981a, Yamamoto and Oguti, 1982). The propagating pulsation tends to occur at dawnside and is correlated with geomagnetic pulsation (Oguti et al., 1981b). Figure 3 show selected snapshots of Movies 1-6, which show high-speed imaging of pure/expanding pulsation, streaming pulsation, and non-pulsating substructures. See Section 2.2.3 for details.

The on-off temporal sequence of pulsations can be classified into three types: (1) Positive pulsation has "on" time longer than "off" time; (2) negative pulsation has "on" time shorter than "off" time; (3) irregular burstlike pulsation and complex mixtures of (1) and (2) (Yamamoto, 1988). The "on" time has two primary populations $(\sim 0.2-0.5 \mathrm{~s}$ and $2-6 \mathrm{~s})$. The pulsation period has a wide range as mentioned above, but the pulsation "on" time is fairly constant across different types of patches, while the pulsation "off" time is variable (between nearly zero and longer than $1 \mathrm{~min}$ ) (Yamamoto, 1988). Pure, streaming and propagating pulsation has $\sim 2-6 \mathrm{~s}$ of "on" time. A more rapid pulsation $(\sim 0.2-0.5 \mathrm{~s})$ is found for flash and $3-\mathrm{Hz}$ modulation. Those rapid pulsations do not necessarily occur coherently over a patch but occur at substructures of patches (Nishiyama et al., 2016). The $\sim 3 \mathrm{~Hz}$ modulation appears in more than $50 \%$ of all pulsating auroras in the midnight and morning sectors, and the amplitude of modulation using panchromatic imaging ranges up to $20 \%$ (Royrvik and Davis, 1977).

\section{Dayside diffuse and pulsating aurora}

Most pulsating auroral studies concern the nightside, and much of this chapter covers nightside pulsating aurora. But here we review dayside diffuse and pulsating aurora, which is also associated with substorms. Typically, these observations have been at high latitudes (i.e., near cusp latitudes), as opposed to the traditional occurrences, which tend to be near the equatorward edge of the auroral zone.

There have been, however, at least a couple of notable exceptions. First, Royrvik and Davis (1977) noted that "all-sky camera data from Byrd Station (near the equatorward boundary of the auroral oval) demonstrate that the pulsating aurora can extend eastward from the darkside auroral oval around the noon meridian or even beyond". Note that, because of the relative orientations of the magnetic and geographic poles in the southern hemisphere, stations in the auroral zone remain in darkness 24 hours per day.

In addition, Berkey (1978) presented photometric and riometer observations obtained just after twilight (1300-1600 MLT) at College, Alaska, and showed the occurrence of pulsating aurora in the afternoon sector. The events were detected by simultaneously observing the sky with a $428 \mathrm{~nm}$ photometer and a riometer. They compared $428 \mathrm{~nm}$ emissions to sunlight (actually, to twilight). As the sun set, a pulsating aurora signature was observed corresponding to absorptions that were present before the optical signatures could be observed, due to sunlit conditions. With this arrangement, only a half dozen events were observed during 
the winter of 1967-68. Still, the results suggest that the pulsating aurora generation mechanism can operate on nearly global scales.

At high latitudes (on the dayside), pulsating aurora was first reported by Brekke and Pettersen (1971), using data from Spitzbergen. In that report, they described this aurora as seldom being more than $5 \%$ of the total $427.8 \mathrm{~nm}$ emission and having pulsating periods from 25-40 seconds. Occurrence rates varied with magnetic local time, with a maximum being slightly before magnetic noon.

Craven and Burns (1990) examined data from Davis, Antarctica (ILAT of 74.5 degrees), using optical emissions at $557.7 \mathrm{~nm}$. At this wavelength, the authors typically found an enhancement of $250 \mathrm{R}$ (or less) on a $1 \mathrm{kR}$ background and also noted that pulsating periods tended to be 20-30 s, quite similar to Brekke and Pettersen (1971). Occurrence rates peaked near $14.5 \%$ with a peak in occurrences near 1330-1400 magnetic local time (i.e., postnoon).

Wu and Rosenberg (1992) addressed the apparent discrepancy reported by these authors, regarding whether the peak in occurrence comes before or after magnetic noon. These authors examined $427.8 \mathrm{~nm}$ emissions from South Pole station and found a single-peaked distribution at magnetic noon during quiet times and a double-peaked during moderate activity at 1000-1030 MLT and 1400-1600 MLT. They note a number of variables that could account for ow their results differ from that of Craven and Burns (1990) and Wu and Rosenberg (1992), emphasizing differences in MLT of the observing times at these stations.

\subsection{Driving processes}

The mechanism that drives pulsating aurora had long been thought to be associated with VLF waves near the equator that scattered energetic electrons in that region (Tsuruda et al., 1981). Rocket observations indeed found that pulsating aurora is primarily driven by modulating electron precipitation of energies above a few keV (Johnstone, 1978; McEwan et al., 1981). As described in Section 2 and in recent review papers by $\mathrm{Li}$ et al. (2013) and $\mathrm{Ni}$ et al. (2016), quasi-periodic precipitation into the upper atmosphere is caused by a group of chorus waves in the equatorial magnetosphere that turn on and off quasi-periodically in $\sim 10 \mathrm{~s}$ periodicity and scatter plasma sheet electrons into the loss cone. Thorne et al. (2010) was able to show that, specifically, lower-band chorus is most effective for electron precipitation at higher energies $(>7 \mathrm{keV})$ and that upper-band chorus is more important for energies below $\sim 3 \mathrm{keV}$. Figure 4 illustrates this process.

Confirmation of this process was provided by Nishimura et al. (2010), who showed evidence of lower-band chorus waves, measured by THEMIS spacecraft, in conjunction with ground-based optical observations of pulsating aurora. Correlation between chorus and pulsating aurora last for hours and are highest among other types of waves (Nishimura et al., 2018), giving a firm evidence that the chorus-pulsating aurora connection is not spurious. The chorus-pulsating aurora connection allows to test accuracy of magnetic field models and evolution of magnetic field geometry (Nishimura et al., 2010, 2018, Kawamura et al., 2019). 
Evidence of equatorial electron scattering above pulsating aurora was presented by Jaynes et al. (2013), who showed data from the Magnetospheric Electron Detector (MAGED) on the GOES 13 satellite while it was located in a position where its magnetic footprint mapped to the ground in a region with pulsating aurora. These data included a direct correlation between diffuse luminosity fluctuation periods and particle pulsation periods over an energy range of 30 to 50 $\mathrm{keV}$ and, to a lesser degree, $50-100 \mathrm{keV}$.

Finally, Kasahara et al. (2018) showed data from the Japanese ARASE satellite as it passed over The Pas (in Manitoba, Canada) where pulsating aurora was observed, with chorus waves being highly correlated with energetic electrons spanning from $10 \mathrm{keV}$ to $30 \mathrm{keV}$. Individual elements of chorus waves would create more rapid modulation of precipitating electrons and have been shown to explain the 3-Hz modulation (Ozaki et al., 2015). Such a comprehensive measurement is both unique and important, as it provides direct confirmation of the theory.

The cause of the chorus modulation is, of course, of interest and a number of authors have determined that the periodicity of pulsating aurora has a latitudinal dependence. Such a situation might arise, for example, if chorus waves modulation is driven by field-line resonances (Thomas and Stenbaek-Nielsen, 1981; Duncan et al., 1981; Creutzberg et al., 1981). Much more recently, Spanswick et al. (2005) showed that pulsations in the cosmic noise absorption (indicative of energetic electron precipitation) correlate with field-line resonances, and Jaynes et al. (2015) showed in-situ observations of structured chorus waves in conjunction with an apparent field-line resonance, along with ground-based observations of pulsating aurora, although the modulation of chorus waves occurs at half the period (twice the frequency) of the ULF waves. The resonance in this case is a poloidal mode, which would include compressional wave power that might drive the oscillations.

A similar result was obtained by Motoba et al. (2017), but with regard to dayside aurora. These authors correlated all-sky imager observations of pulsating aurora with compressional Pc3 waves, which they suggest are driven by upstream waves.

As mentioned above, patch motion can be characterized by the $E \times B$ drift, and magnetic drifts of energetic electrons cannot explain its motion. These properties suggest that patch motion reflects structure of cold plasma in the magnetosphere rather than drifts of energetic electrons. While it is still unknown how such cold plasma regions form and regulate auroral pulsation, satellite observations have shown modulating low-energy plasma fluxes that suggest to originate as plasma outflows from the ionosphere and to modulate wave growth rates (Nishimura et al., 2015; Liang et al., 2015). Substantial ionization and heating in the ionosphere are associated with pulsating aurora (Hosokawa and Ogawa, 2015; Liang et al., 2018), and such processes may be the source of plasma outflow. Waves going to the southern (northern) hemisphere interact with electrons moving to the northern (southern) hemisphere. Waves do not necessarily propagate toward both hemispheres at the same time, and this can explain incoherence of pulsations in the two hemispheres, although overall morphology of pulsating aurora has conjugacy (Fujii et al., 1987; Watanabe et al., 2007).

Spectroscopy of pulsating aurora also supports that the typical energy of pulsating aurora is above a few $\mathrm{keV}$ (McEwen et al., 1981). Pulsating aurora is dominated by emission at the $557.7 \mathrm{~nm}$ wavelength, and the intensity ratio between 557.7 and 427.8 is about $4-5$. Emission at $630.0 \mathrm{~nm}$ is generally weak and unchanged during pulsations. However, some events are associated with discernible $630.0 \mathrm{~nm}$ emission coincident with the pulsations, although the level 
of intensity modulation is much smaller than at the other wavelengths. In such cases, pulsating aurora involves a small amount of $<\mathrm{keV}$ electrons (Eather, 1969; Liang et al., 2016).

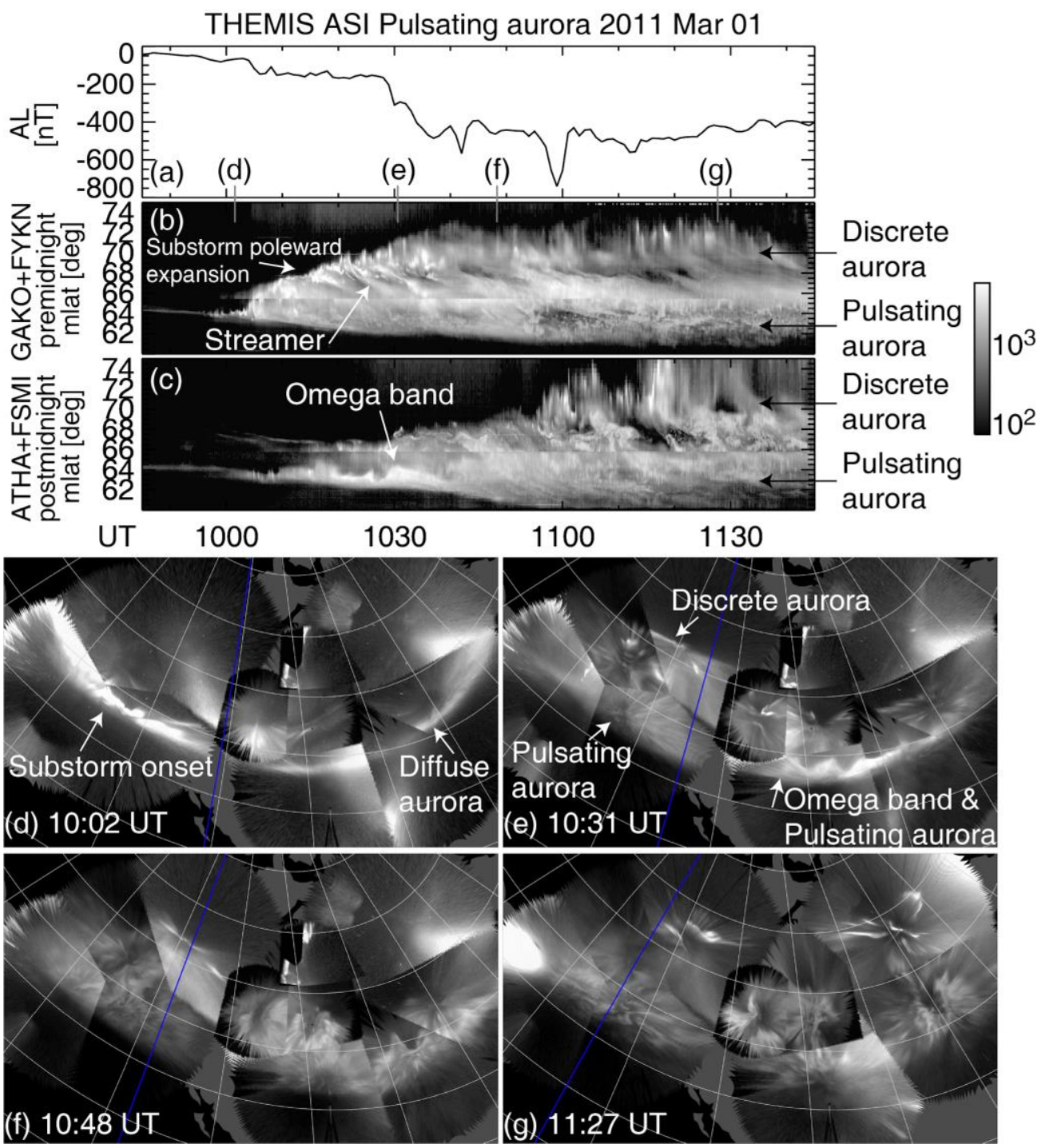

Figure 1. Pulsating aurora distribution and evolution during the 10-11 UT, 1 March 2011 substorm, detected by the THEMIS all-sky imagers.

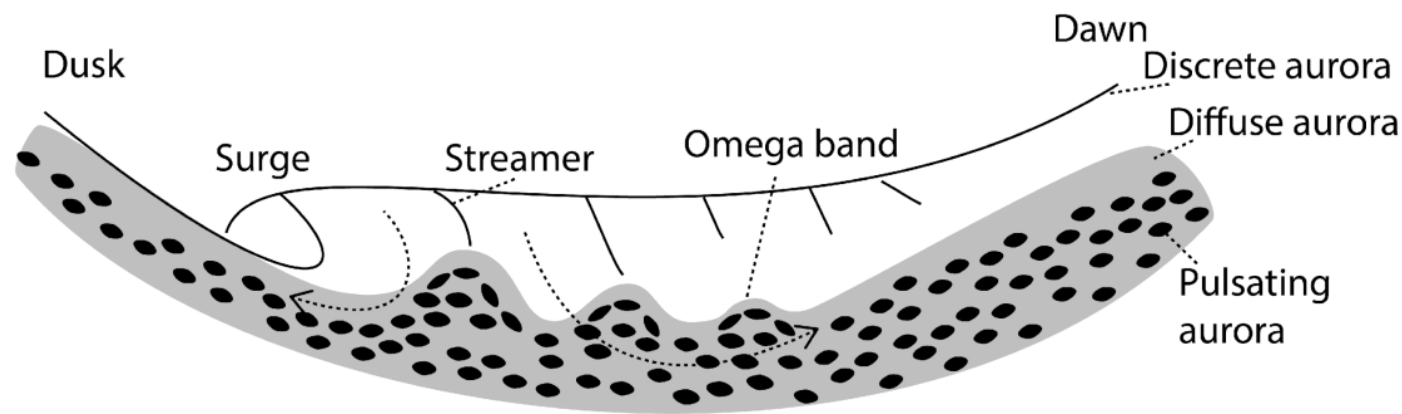

Figure 2. Schematic illustration of pulsating auroral distribution in substorm aurora. 

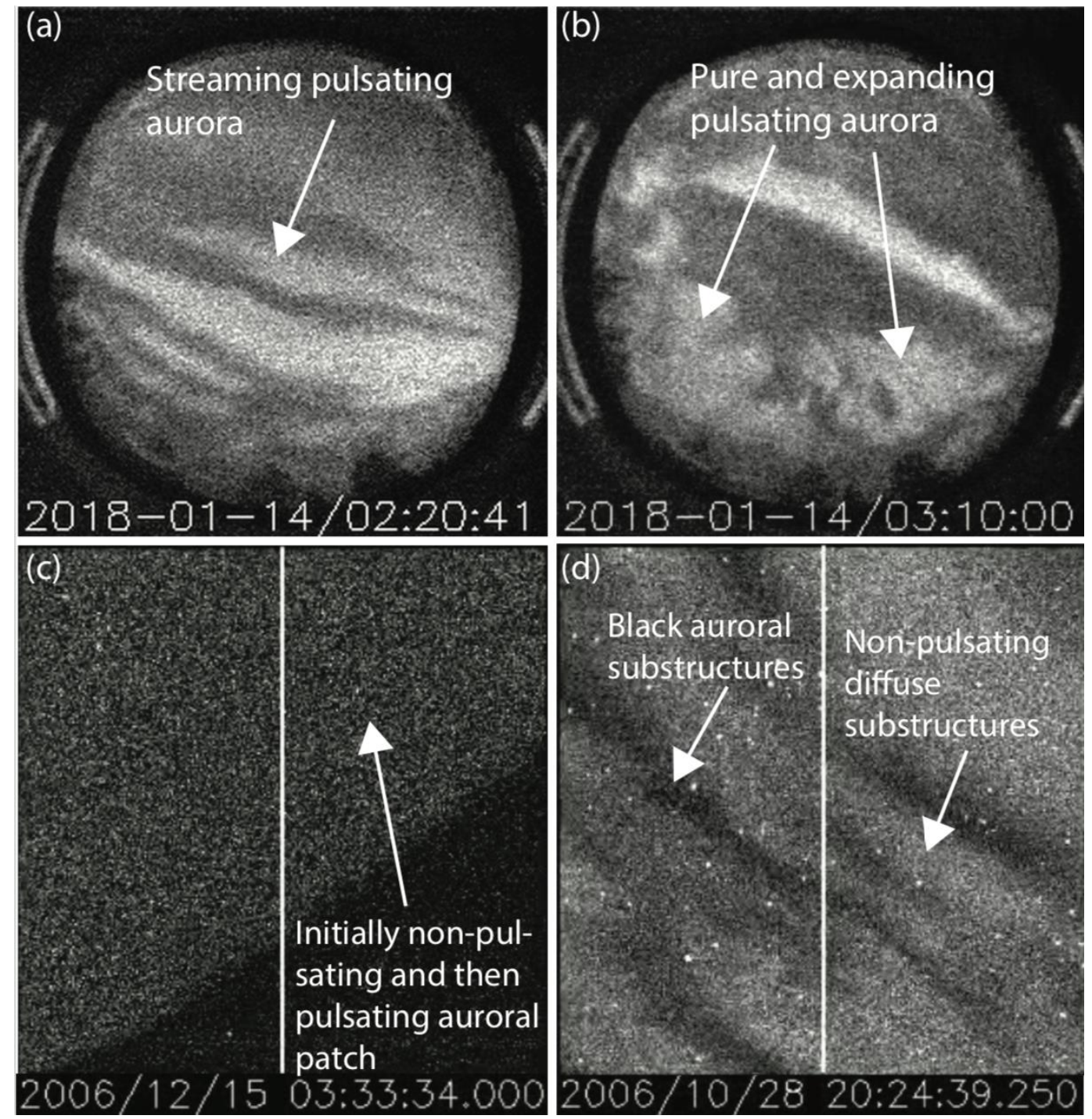

Figure 3. Selected snapshots of diffuse and pulsating aurora. (a) Streaming pulsation (Movies 1 and 3), (b) pure and expanding pulsation (Movies 2 and 4), (c) pure pulsation and its moving boundary (Movie 5), and (d) non-pulsating substructures within pulsating aurora (Movie 6). 


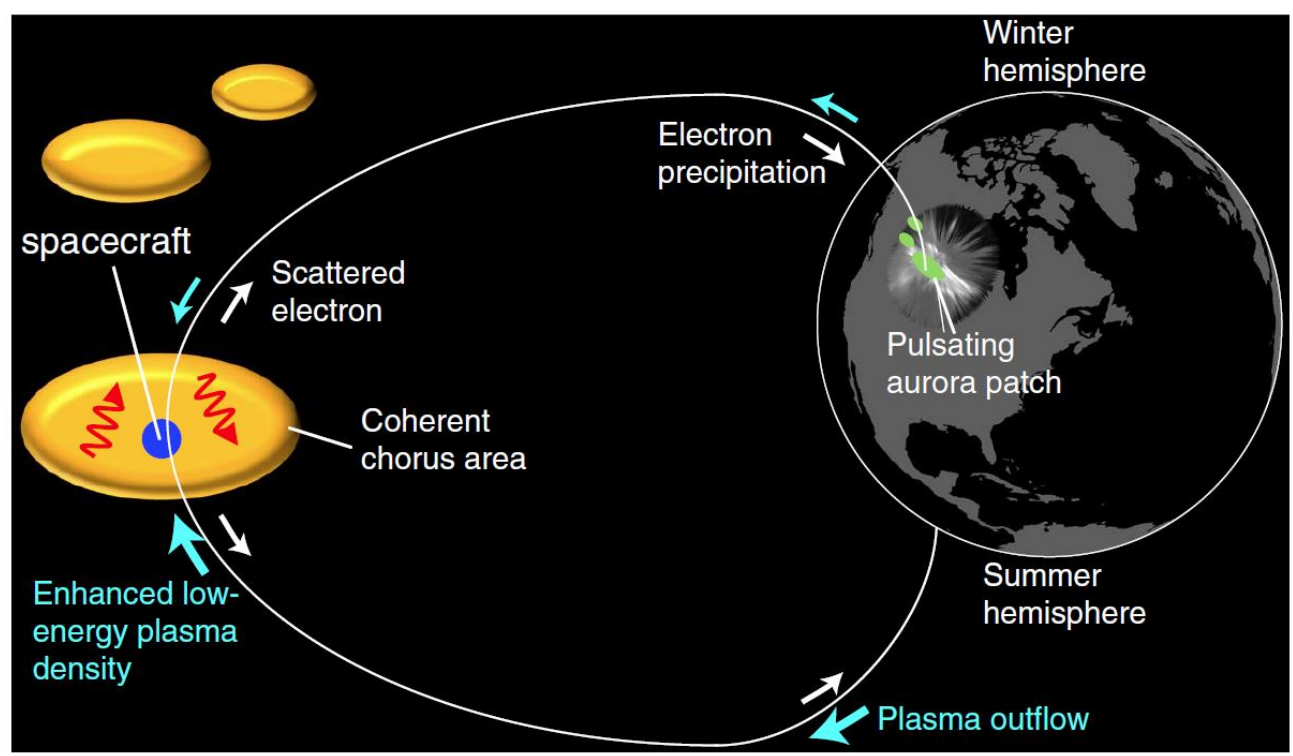

Figure 4. Schematic illustration of chorus and pulsating aurora connection (Nishimura et al., 2015). 


\section{Recent advances}

\subsection{Observation technique}

Diffuse aurora appears quite faint in ground-based all-sky images except during westward travelling surges (Lui et al., 1977). Pulsating aurora occurs within regions of diffuse aurora and can be measured by the same instruments but with a high cadence to capture high frequency pulsations. Historically, these forms of aurora have been measured using direct visual observations and photographic images (Lessard, 2013 and references therein), all-sky imagers, television and image intensifier camera systems, meridian scanning photometers, and spectrometers. Apart from the optical signatures, measurements have been made of alternate signatures such as ionospheric electron density using radars (Kirkwood et al., 1988), cosmic noise absorption with riometers (Arnoldy et al., 1982; Berkey et al., 1980), ionospheric currents with magnetometers (Arnoldy et al., 1982; Oguti and Hayashi, 1984; Michell and Samara, 2015), electron and ion precipitation using particle detectors or electrostatic analyzers onboard sounding rockets (Bryant et al., 1969) and spacecraft (Evans et al., 1987), and X-ray bremsstrahlung emissions using X-ray detectors on air balloons (Sørensen et al., 1973).

Technological advances in the past couple of decades have enhanced the capabilities of the above measurement techniques. All-sky imager networks that had used photographic films, are now entirely digital cameras with solid-state optical detectors. Scientific grade CCDs, that can measure both weak and intense emissions simultaneously, are used in camera networks such as MIRACLE in Scandinavia (Sangalli et al., 2011), and in THEMIS Ground-based Observatory (GBO) in North America (Mende et al., 2008). Electron multiplication CCD (EMCCD) detectors are being used in more recent experiments, which are highly sensitive and have better frame rates. Most cameras use narrow-band filters that allow quantitative measurement of intensities from particular auroral emissions. Auroral Structure and Kinetics (ASK) is a multi-spectral imager consisting of three EMCCD cameras with identical, narrow $\left(3^{\circ}\right.$ or $\left.6^{\circ}\right)$ fields-of-view centered on magnetic zenith (Dahlgren et al., 2008). Each ASK camera is fitted with a different narrow passband interference filter, in a combination designed to image the energy and flux of the electron precipitation in fine-scale auroral features at up to 32 frames per second (Lanchester et al., 2009; Dahlgren et al., 2016). The Multispectral Observatory Of Sensitive EMCCDs (MOOSE) suite of imagers was deployed in Poker Flat, AK as a pathfinder for future larger arrays for exploring the electrodynamics of the aurora from ground multi-spectral imaging. It consists of five Andor Ixon DU-888 EMCCD imagers that have a 1024×1024 pixel chip each, with internal binning and sub-framing capabilities that allow trade-offs between temporal and spatial resolution (details in Michell et al., 2014). These imagers are well suited to high spatial and temporal resolution auroral morphology studies (such as, Michell et al., 2012). However, the driving force behind this observatory was the simultaneous use of these imagers with filters of different wavelengths for a multi-spectral view of the aurora in real time. To that end, each imager has telecentric optics to allow the use of narrowband pass filters for two dimensional auroral photometry studies which are actively used to infer the average energy and total energy flux of the precipitating electron distribution, such as Grubbs et al., (2018). 
Modern auroral TV-cameras use image-intensified charge coupled device (ICCD) detectors, and are capable of obtaining 25-30 frames per second, and are better at measuring faint aurora than their older counterparts. Scientific complementary metal-oxide semiconductor (sCMOS) cameras, that allow higher frame rates with similar sensitivities as CCDs, have been used to observe the finescale morphology of aurora. An NIPR-CMOS system, installed in February 2014 at Poker Flat Research Range, is capable of measuring auroral emissions at a high resolution of $2048 \times 2048$ pixels, at 100 frames per second, within a field of view corresponding to $25.6 \times 25.6 \mathrm{~km}$ at $100 \mathrm{~km}$ altitude (Kataoka et al., 2015).

Photometers measure intensity of light, through a tube consisting of a lens, filter and a detector. Meridian scanning photometers, with filters, scan the magnetic meridian and produce elevation profiles of auroral emissions at different wavelengths typically: $O^{+} 557.7 \mathrm{~nm}$ and $630.0 \mathrm{~nm}, \mathrm{~N}_{2}^{+} 427.8 \mathrm{~nm}, \mathrm{H}_{\beta} 486.1 \mathrm{~nm}$ (Deehr \& Lummerzheim, 2001; Johnston, 1989; Unick et al., 2017). Spectrographs, measure the spectrum of the aurora with light collected through a narrow slit, and focused through a grating onto a detector. An imaging spectrograph, such as the CEDAR Optical Tomographic Imaging Facility (COTIF), measures all elevations simultaneously, with a time resolution identical for all emission wavelengths dictated by the instrument sensitivity (Semeter et al., 1999).

One area of substantial interest has been to study the altitude profiles of auroral emissions. These can be estimated using a few different techniques: 1) multiple cameras viewing the same volume of sky from different directions (Whiter et al., 2013) in combination with tomography-like methods (Enell et al., 2012; R. Kataoka et al., 2016), 2) spectral measurements of the same region of the sky (Semeter et al., 1999), 3) space-based visible and UV tomography (Comberiate et al., 2007; Solomon et al., 1984). The Auroral Large Imaging System in Scandinavia is specifically built for the first technique and is the first system in the world that can produce three-dimensional luminosity distribution of aurora (Brändström, 2003, Tanaka et al., 2011). ALIS is capable of measuring scale-sizes down to $100 \mathrm{~m}$ at a $5 \mathrm{sec}$ temporal resolution, and its imagers are equipped with filter wheels that study visual and sub-visual aurora. The system, which can be remotely-controlled via internet can be made to point in any direction.

Identifying diffuse and pulsating aurora automatically is challenging, and several automatic auroral image classification techniques have arisen over the last two decades using techniques from computer vision, pattern recognition, and machine vision. Over the last few years, advancements in machine learning and access to predefined algorithms have enabled the application of deep neural networks on large auroral-image datasets. Using this technique, Clausen \& Nickisch, (2018) were able to classify images into no aurora, cloudy, moon, arc, diffuse and discrete with about $82 \%$ accuracy. Tracking the convection of auroral forms has also been a topic of increasing interest in the past decade. Grono et al., (2017) used a technique based on wavelet filtering to track the velocity of pulsating aurora patches.

The ionospheric effects of pulsating and diffuse aurora have been studied using a few instrument types. Fabry-Perot interferometers (FPI) are widely used to estimate ionospheric wind velocities and temperatures by measuring the atomic line profiles of low-light emissions. These instruments have been employed to study the effect of pulsating aurora on the variation of wind velocities (Oyama et al., 2010; Oyama et al., 2016). A novel experiment was carried out using an eightmicrophone array of ground-based infrasonic receivers at Fairbanks, Alaska, to 
correlate atmospheric acoustic pulsations with pulsating aurora (Wilson et al., 2005).

Another extensively used tool to study the signature of aurora in the ionosphere are the Incoherent Scatter Radars (ISRs). ISRs can estimate a number of different quantities varying in altitude by using model estimates of the neutral atmospheric composition and ionospheric chemistry. The EISCAT radar system in Northern Europe and the Advanced Modular ISR (AMISR) systems in North America are the two main ISR systems currently used to study the ionosphere in the auroral regions. The following quantities are derived from the power spectra of the backscattered radar waves: the altitude profiles of electron density, electron and ion temperature, and line of sight velocity (Robinson, 2004). The AMISR systems have the ability to probe multiple points in the ionosphere simultaneously using the electronically steerable phased-array system (Nicolls and Heinselman, 2007). As a result, with appropriate assumptions they can estimate the ion velocities in the F-region, and neutral-wind velocities in the E-region. Using electron density profiles from ISRs it is possible to estimate Hall and Pedersen conductivities in the ionosphere (Hosokawa et al., 2010; Kirkwood et al., 1988), energy spectra of precipitating electrons (Fang et al., 2010; Semeter and Kamalabadi, 2005; Sivadas et al., 2017), ionospheric electron heating (Liang et al., 2018), and Hall and Pedersen currents. Atmospheric radars such as PANSY in Antarctica (Sato et al., 2014) can be used to identify deep mesospheric ionization during diffuse or pulsating aurora (Kataoka et al., 2019). SuperDARN, a global network of highfrequency radars in the Arctic and Antarctic, uses coherent scatter signals to study ionospheric plasma convection. Recently, it was shown that attenuation in the background atmospheric radio noise during solar proton events can be used to estimate ionospheric absorption similar to riometers (Bland et al., 2018), and the same technique can be used to detect energetic precipitation within diffuse or pulsating aurora (Bland et al. 2019). Riometers are passive receivers operating in the range of $30-40 \mathrm{MHz}$, and are used to measure the extent to which comic radio noise is absorbed by the ionosphere. The absorption is primarily a result of the Dregion ionosphere, ionized by high energy precipitation, UV and X-rays. In the last two decades, imaging riometers have been built that can be used to image the spatial structure of energetic precipitation (Honary et al., 2011; Kosch et al., 2001; McKay et al., 2018).

Besides ground-based instruments, space- and air-borne experiments have also contributed substantially to our understanding of the diffuse and pulsating aurora. Of particular importance are observations of particle energy spectra and waves by THEMIS and GOES-13 in the magnetosphere, and optical images by the low-earth orbiting satellite Reimei and e-POP (Lui et al., 2015). Electric field and electron temperature measurements from Swarm (Knudsen et al., 2017), measurements of Chorus, Hiss, and EMIC waves in the magnetosphere using spacecraft such as CRRES, THEMIS and RBSP (Nishi et al., 2018), particle measurements by low-earth orbiting satellites such as DMSP, FAST, NOAA, and ARASE (Kasahara et al., 2018), X-ray images from the PIXIE on-board the lowearth orbiting POLAR satellite, ultra-violet images from WIC on-board IMAGE (Mende et al., 2002) and GUVI on-board TIMED (Zhang et al., 2005), are among the other datasets available to study the source and signature of pulsating and diffuse aurora. Though rare, early rocket-borne experiments recorded energy flux variations of precipitating electrons that correlate with optical observations of pulsating aurora (McEwen et al., 1981). 


\subsection{Observations}

\subsubsection{Pulsating auroral properties}

\section{Large-scale occurrence and duration}

Jones et al. (2011) reported that the most probable duration of pulsating aurora events is between 90 and 120 minutes yet events persisting for several or more hours are common. Within their set of 74 events spread across 119 days of good optical data from Gillam THEMIS all-sky imager, the likelihood of observing pulsating aurora at pre and post-midnight is $14 \%$ and $54 \%$, respectively, indicating that this is predominantly a morning-sector phenomenon. Jones et al. (2013) highlighted a particularly long-lived event which covered more than 10 hours magnetic local time and endured for at least 15 hours until the cameras shut down at sunrise. Cameras are often unable to observe the end of morning-sector pulsating aurora events, making it impossible to accurately determine their duration or occurrence (See Section 1.1 for dayside measurements). Using a set of 398 events identified in a decade of MIRACLE ASC data, Partamies et al. (2017a) found the median lifetime of pulsating aurora to be 1.4 hours, in agreement with Jones et al. (2011). They highlighted the conservative nature of these estimates using all-sky images from Svalbard which captured pulsating aurora continuing beyond what could be observed by the MIRACLE ASCs in Lapland. In fact, the SuperDARN detection method by Bland et al. (2019) reported 1.16 hours longer median duration $(2.83 \mathrm{~h})$ as compared to optical observations $(1.67 \mathrm{~h})$. As the radar detection is independent of optical observing conditions, a seasonal occurrence variation could be revealed showing the highest occurrence rates during the winter months (up to 50\% at 4-5 MLT).

\section{Altitude of patches}

The altitude of aurora is primarily inferred through either stereoscopic imaging or the measurement of electron density profiles. Auroral stereoscopy is the triangulation of structures simultaneously observed from multiple locations. Electron density profiles can be used to approximate auroral altitude since peak emission and electron density are closely related. Apart from these, other methods have been used to less-accurately establish the range of altitudes that pulsating aurora can originate from (Liang et al., 2016, Grandin et al., 2017).

Kataoka et al. (2013) demonstrated stereoscopic auroral imaging utilizing ground-based digital single-lens reflex (DSLR) cameras, which are cheaper and more portable than scientific-grade CCDs. Applied to two case studies, a discrete ray structure and pulsating aurora, they found broad altitude distributions which peaked above and below $100 \mathrm{~km}$ altitude, respectively. Kataoka et al. (2016) used this same technique with sCMOS cameras to perform the first-ever stereoscopic auroral imaging at 100 frames per second, determining the emission altitude of a pulsating patch to be $85-95 \mathrm{~km}$ and that it could vary by $10 \mathrm{~km}$ over 5 seconds. The overlapping fields-of-view of the MIRACLE all-sky imager network allowed Partamies et al. (2017a) to stereoscopically observe a decrease in peak emission height by approximately 8 $\mathrm{km}$ during the onset of a pulsating aurora event, lowering the hardest $10 \%$ of 
precipitating electrons to approximately $90 \mathrm{~km}$. This was further found to apply primarily to the events occurring towards the end of substorm recovery phases when the patch sizes were systematically decreasing (Partamies et al., 2019).

While studying thermospheric wind variations within pulsating patches using a Fabry-Perot interferometer, Oyama et al. (2016) observed electron density peak heights in simultaneous EISCAT observations between 93 and $100 \mathrm{~km}$ with a maximum at $96 \mathrm{~km}$. Using high-frequency EISCAT data Hosokawa and Ogawa (2015) separately measured the altitude profile of pulsating aurora during its bright and dim states and identified a $10 \mathrm{~km}$ difference that is lost when the measurement is more commonly performed with lower-resolution radar data.

Grandin et al. (2017) used the Sodankylä Ion-Neutral Chemistry model to estimate the amplitude of cosmic noise absorption (CNA) modulation during pulsating aurora, finding that uniform modulation of the ionization profile between 80 and $150 \mathrm{~km}$ matched their CNA observations. Close correlation was found between the temporal evolution of CNA and optical emission intensity. More recently, a good correlation between optical emission intensity and CNA was observed during amorphous pulsating aurora (Grono and Donovan, 2018) but not during patchy pulsating aurora (Yang et al., 2019). Limited to a single event with an overpassing satellite their results suggest that amorphous pulsating aurora is associated with higher energy precipitation (peaking at $\sim 20 \mathrm{keV}$ ) than patchy pulsating aurora (peaking at $\sim 9 \mathrm{keV}$ ).

Liang et al. (2016) examined pulsating patches imaged by a $630 \mathrm{~nm}$ redline REGO all-sky imager and found that when compared to "white light" THEMIS all-sky imager data mapped to $110 \mathrm{~km}$ altitude, the redline pulsations overlapped best at an average altitude of $156 \mathrm{~km}$. This is noticeably lower than steady-state redline auroras, which are conventionally mapped to $230 \mathrm{~km}$ (Jackel et al., 2003).

\section{Patch evolution}

Diffuse auroras also involve fine-structures at a few to a few tens of $\mathrm{km}$ (Sergienko et al., 2008; Shiokawa et al., 2009). These fine-scale structures were suggested to form along the western edges of eastward drifting pulsating auroral patches when the convection drift slows down, and to grow from RayleighTaylor instability at the boundary of a drifting patch. Fukuda et al. (2016) reported rapid, often repetitive expansions around the edges of patches related to their intensity modulation. The expansion speed was typically $10 \mathrm{~s} \mathrm{~km} / \mathrm{s}$, comparable to Alfvén speeds, indicating that this phenomenon could arise from the slow and fast-mode Alfvén waves. Samara and Michell (2010) observed that pulsating patch intensity is not symmetric in time, but rather increases more slowly than it decreases. Similarly asymmetric intensity rise and fall times were measured by Dahlgren et al. (2017), who reported an average of 1.6 and $1.4 \mathrm{~s}$, respectively. Based on analysis of optical and radar data of individual patches, precipitation energy and energy flux were found to be $60 \%$ lower during off times mainly due to the reduction of high-energy particle flux. Despite this, the energy of precipitating particles remained greater than a few keV throughout off times. The presence of high energy precipitation during both on and off times led the authors to suggest that the same precipitation mechanism is in effect during both time periods. No high-frequency modulation was detected in the two 
studied events. The speed of patch evolution can be a useful criterion for differentiating pulsating aurora.

\section{Pulsating aurora relation to substorms}

Pulsating aurora has been recognized as a characteristic of post-onset aurora. While approximately $60 \%$ of pulsating aurora observations have been collected during substorm recovery phases (Partamies et al., 2017a), they are not uncommon in expansion phases. Pulsating auroral patches observed during substorm expansion phases have a tendency to grow in size, while the more common patches seen during the substorm recovery phases mainly decrease in size (Partamies et al., 2019). Pulsating auroral patches have recently been found within the growth phase auroral arc of a substorm (McKay et al., 2018).

It was noted by Weygand et al. (2015) and Partamies et al. (2017b) that every auroral omega band is accompanied by simultaneous, or nearly simultaneous, pulsating aurora either directly inside the auroral omega structure or further equatorward within the same band of diffuse aurora. This is not true of the converse, since the existence of pulsating aurora does not require particularly high geomagnetic activity (Partamies et al., 2017a) while the occurrence of omega bands does imply above average substorm activity (Partamies et al., 2017b). In particular, torch-like omega bands have been observed to consist of pulsating aurora (Sato et al., 2015). Their passage is typically followed by appearance of pulsating aurora, but can sometimes be preceded by pulsating aurora as well (Sato et al., 2017). The relation between omega bands and pulsating aurora was found to hold for eastward-expanding auroral surge (EEAS) events, which also take place shortly after substorm onsets (Tanaka et al., 2015).

\section{Other patch characteristics}

The thickness of pulsating auroral patches can be estimated from electron density altitude profiles which reveal where particle precipitation has ionized neutral atmospheric particles. Utilizing electron density profiles measured by PFISR, Jones et al. (2009) observed a pulsating patch approximately $15-25 \mathrm{~km}$ thick. This result was corroborated by Hosokawa and Ogawa (2015) who observed similar thickness in EISCAT electron density profiles of four pulsating auroral patches.

The lifetimes of pulsating auroral patches are most commonly measured on an individual basis, and efforts that could allow their determination en masse have been few. While implementing an automatic algorithm to track pulsating patches, Grono et al. (2017) found that the number of images unique patches were identified in could function as a proxy for patch lifetime. It was observed that the lifetime of the shortest-lived structures was less than 1 minute, while the longest-lasting could endure for 10s of minutes.

Humberset et al. (2018) quantitatively and qualitatively assessed the evolution of four patches over a portion of their lifetimes, measuring the stability of their shape and coherence of their pulsations. They found that $85-100 \%$ of the patch shape persist for 4.5-8.5 minutes. In addition, detailed characteristics of these patches were provided, including their emissions and apparent size which ranged 
approximately from $2.7-3.8 \mathrm{kR} \mathrm{km}^{-2}$ and $1000-4800 \mathrm{~km}^{2}$, respectively. Similar patch sizes were later reported by Partamies et al. (2019) and Ozaki et al. (2019). It was noted by Grono et al. (2017) that while pulsating patches have been seen to follow ionospheric convection (Yang et al., 2015, 2017), all structures that could be defined as pulsating patches do not move in the same manner. Grono and Donovan (2018) proposed three categories of pulsating patches based on the stability of their shape and the spatial extent of their pulsations. Amorphous Pulsating Aurora (APA) describes rapidly evolving pulsating features that are generally difficult or impossible to track between successive images captured at a 3 second cadence. Patchy Pulsating Aurora (PPA) and Patchy Aurora (PA) are long-lived structures that can persist for 10s of minutes, but PA does not pulsate. These two types of aurora are clearly related, and appear to differ only by the existence of a modulating mechanism in their source region. While the apparent motion of APA appears unrelated to convection, Grono and Donovan (2018) revisited the events of Yang et al. (2015) and Grono et al. (2017) and found that they reported PPA and PA patches moving with convection.

Grono and Donovan (2019) found that pulsating aurora does not occur poleward of the proton aurora. Amorphous pulsating aurora appears within and equatorward of the proton aurora, while patchy and patchy pulsating auroras predominantly form equatorward of the optical b2i boundary (Donovan et al., 2003). The optical b2i is a variant of the b2i boundary (Newell et al., 1996), defined by the rapid decrease in downward proton fluxes. This boundary is the ionospheric marker of the isotropy boundary (e.g., Sergeev et al., 1983), indicating the transition between stably trapped protons and those scattered by magnetic field curvature. That patchy and patchy pulsating auroras primarily form equatorward of this point suggests that mechanism and conditions responsible for their structuring occurs in the region of mostly dipolar magnetic field.

Yang et al. (2019) reported evidence that APA was associated with higher energy electron precipitation than PPA. They investigated cosmic noise absorption (CNA) associated with APA and PPA, finding that CNA is systematically higher during APA than PPA and better correlated with its brightness. Furthermore, they found one conjunction between the FAST satellite and both APA and PPA. The APA feature had higher energy precipitation than the PPA feature.

Pulsating aurora is not generally coherent between the two hemispheres (Watanabe et al., 2007). Although pulsating aurora has the tendency to occur simultaneously on both hemispheres (Partamies et al., 2017a), the shape of the auroral form is generally different between the two hemispheres, and there is little or no interhemispheric correlation in the intensity variations. This property suggests that waves do not occur simultaneously in the northern and southern hemispheres but have different frequencies and sizes so that precipitating particles are modulated differently in different hemispheres.

\subsubsection{Morphology of non-pulsating diffuse aurora, small-scale structures}

Fine small-scale structures are sometimes seen within non-pulsating diffuse aurora both in the dayside and nightside, while viewed through sensitive detectors. They are often termed structured diffuse aurora (SDA). In the dayside, they are most often observed at magnetic local noon. Two types of SDA have been identified to coexist within this region: stripy or patchy forms that drift towards higher latitudes and forms adjacent to discrete aurora that moves slowly along with 
it. Han et al. (2017) found that the latter has an increased $\mathrm{He}^{2+}$ concentration, which find their way into the magnetosphere from magneto-sheath, suggesting that the magneto-sheath particles may play an important role in producing the dayside diffuse aurora. The stripy and irregular forms of dayside aurora seem to be produced by electrons of energy $\sim 1-10 \mathrm{keV}$ (Han et al., 2015). Simultaneous measurements from an all-sky imager and THEMIS spacecraft by Nishimura et al. (2013) suggests that the SDA patterns reflect the spatial distribution of whistlermode waves and ambient plasma density near the magnetic equatorial plane.

One of the earliest reports on the statistics of narrow discrete arcs by Maggs and Davis (1968), may have included a large fraction of nightside SDAs according to Stenbaek-Nielsen et al., (1999). Nightside SDA are regular, parallel auroral stripes brighter than the background luminosity observed mostly during the recovery phase of substorms (Sergienko et al., 2008). These aurorae have been shown to be associated with electrons $\geq 8 \mathrm{keV}$ scattered into the loss-cone from trapped magnetospheric particles (Samara et al., 2010). A statistical analysis of about 500 diffuse stripelike structures recorded during 5 events have found the scale sizes of these stripes to be on average about 13-14 km, and with a separation of about 5-23 km between each other (Axelsson et al., 2012). This separation maps to about $75-345 \mathrm{~km}$ in the equatorial plane of the magnetosphere. Using ionospheric equivalent current estimates from ground magnetometers, Axelsson et al. (2012) concluded that the stripes move equatorward at a speed close to zero in the plasma convection frame $(\sim 100-200 \mathrm{~m} / \mathrm{s})$. As in the case of the dayside aurora, the fine structures are understood to be a visual manifestation of cold plasma density or magnetic field structures in the equatorial magnetosphere (Axelsson et al., 2012; Ebihara et al., 2010). A further study on nightside SDAs by Sivadas et al. (2019) showed the diffuse structures within the energetic electron arc (EEA, Sergeev et al. 2012) equatorward of the growth phase arc. This precipitation was concluded to mark the outer radiation belt boundary of the 30$300 \mathrm{keV}$ electrons and, despite the high energies, contribute to $\sim 46 \%$ of the total $427.8 \mathrm{~nm}$ emission.

Apart from the SDA mentioned above, Dahlgren et al. (2012) reported an observation of an unusually narrow filament of $\sim 70 \mathrm{~m}$ width, forming an irregular ring of $\sim 3.8 \mathrm{~km}$ scale size within the diffuse aurora. The authors argue that the source mechanism of this filament is unlikely to be quasi-static potential structures, Alfvén waves, or pitch-angle scattering in the magnetosphere as the primary electron spectra is sharply mono-energetic at $\sim 8 \mathrm{keV}$ with a moderately high energy flux of $\sim 230 \mathrm{~mW} / \mathrm{m}^{2}$, and confined to extremely narrow widths. Peticolas et al. (2002) analyzed six different nights of conjugate optical and satellite data that showed black aurora within uniform diffuse aurora. The black aurora corresponded to electron energy flux dropouts in FAST satellite measurements, with surrounding 
energy flux of electrons $>2 \mathrm{keV}$ in the diffuse aurora. The authors argue that pitch angle diffusion by chorus waves is suppressed in the localized magnetospheric regions leading to the observed black auroral features in the ionosphere.

More recently reported fast auroral transients (McKay et al., 2019) resemble non-pulsating auroral patches, which propagate azimuthally within the CNA arc on the equatorward side of the growth phase arc. The estimated propagation speed of the transients was $\sim 10 \mathrm{~km} / \mathrm{s}$ without a preference between eastward and westward motion. Similarly to the SDAs observed by Sivadas et al. (2019), the auroral transients map to the equatorial plane distance of about 9-12 Re.

\subsubsection{Substructure and fast modulation}

Two main frequency bands have been reported within pulsating aurora during one persistent, several hour event (Samara and Michell, 2010). Lower frequency pulsations, within the range of $50-500 \mathrm{mHz}$, were present in large patches (10$50 \mathrm{~km}$ ) seen by an all-sky imager, while fine-structures observed by a narrow field-of-view imager pulsated at higher frequencies, between $0.5-15 \mathrm{~Hz}$. It was further suggested that pulsation frequency anti-correlates with the size of pulsating structures and correlates with the emission intensity of the pulsating structures. Thus, larger and dimmer auroral structures feature lower pulsation frequencies.

Much faster modulations with frequencies up to $54 \mathrm{~Hz}$ were documented by Kataoka et al. (2012) for one case using a state-of-the-art high-speed imager with a frame rate of 500 frames per second. These are the fastest variations observed to date, and they were seen at the edge of larger pulsating patches. In agreement with Samara and Michell (2010), the pulsation frequency appears to be related to structure size such that the smaller auroral features undergo faster pulsations. Ozaki et al. (2018) reported Particles and Waves in the INner magnetosphere using Ground-based network observations (PWING, Shiokawa et al., 2017) 100 $\mathrm{Hz}$ all-sky imager observations of a patch pulsating which demonstrated rapid evolution on the order of 10s of ms. This behaviour was attributed to successive chorus elements, or possibly to the chorus subpacket structures. It was further demonstrated that the spatiotemporal evolution of a single auroral patch experienced one-to-one correspondence with the individual chorus elements on the timescales of a few hundreds of milliseconds (Ozaki et al., 2019). This gives a more thorough insight into the processes controlling the patch sizes, but requires a theoretical foundation to understand the nature of their structuring.

Three independent and adjacent patches with periods between 4-7 seconds were observed by Nishiyama et al. (2012) with a high-speed camera (100 frames per second). One of the patches experienced high frequency modulation of about $1.5 \mathrm{~Hz}$ in a small region near the centre of the patch. Further, the small size of this patch supports the observation of Samara and Michell (2010) that smaller structures undergo higher frequency fluctuations.

Based on a statistical study of 53 events, Nishiyama et al. (2014) determined that quasi-periodic intensity modulation frequencies most commonly range between $1.5-3.3 \mathrm{~Hz}$. Moreover, modulation frequency was found to correlate with the emission intensity (correlation coefficient 0.58 ), being particularly strong during the morning MLT hours (coefficient 0.67). However, the frequency of pulsating aurora on-off transitions shows no significant correlation with brightness. The high-frequency intensity modulations exist superimposed 
on the quasi-periodic on-off transitions whose frequencies are well below $1 \mathrm{~Hz}$ (2-16 s).

Nishiyama et al. (2016) used a principal component analysis to identify independent substructures within a pulsating auroral patch for the first time. They found that the most rapid fluctuations are localised on sub-structures smaller than $20 \mathrm{~km}$ in diameter which oscillate back and forth relative to the larger patch drifting along $E \times B$. The authors proposed that the oscillation related to the propagation of chorus wave packets. In agreement with Samara and Michell (2010), these substructures underwent higher frequency modulation than was exhibited in the larger patches.

Humberset et al. (2016) identified and tracked six well-defined patches and concluded that they did not pulsate with a regular period. The typical on-time for patches was found to vary between $3-5$ seconds while the typical off-time was shorter, having a median of $0.6 \mathrm{~s}$. Thus, they suggested that the term fluctuating be used instead of pulsating to describe these auroras.

Fritz et al. (2015) carried out a study of black aurora embedded within pulsating patches. They found that black aurora forms an apparent firm boundary between the auroral forms, much like the optical emissions as described by Humberset et al. (2018). This paper also shows evidence of black auroral curls, suggesting the presence of counterstreaming shear flows, perhaps in conjunction with field-aligned currents.

Six movies are available as electronic supplements as examples of fast variation of diffuse and pulsating aurora. Figure 3 shows representative snapshots and highlights the regions of interest. Movies 1 and 2 are obtained by the PWING EMCCD camera at Kevo, Finland at 100 frame/s on 14 January, 2018 at 02:20 and 03:10 UT. Movie 1 shows streaming pulsating aurora, where a series of auroral patches emerge, move rapidly away from original locations, and disappear. Movie 2 shows pure and expanding pulsating aurora, where each patch illuminates simultaneously over the patch or starting from its center. Motion of the pure/expanding pulsating aurora is much slower than for streaming pulsation, and each patch can be traced over several pulsations. When the images are down-sampled to 3-seconds (Movies 3 and 4), Movie 3 does not show the coherent motion seen in Movie 1, while Movie 4 still allows to trace each pulsating auroral patch over a few minutes. APA pulsations could arise from time-aliasing of rapidly-propagating pulsating aurora, and PPA pulsations are slowly drifting patches such as pure and expanding pulsations.

Similar but higher spatial resolution observations have been made with the ASK instrument introduced in Section 2.1, two samples of which are shown as Movies 5 and 6 . The movie shows the rapid dynamics of a pulsating aurora patch seen above Troms $\varnothing$, Norway, on 15 December 2006. The bottom panel shows a sequence of images in $\mathrm{N}_{2} 1 \mathrm{PG}(673.0 \mathrm{~nm}$, a prompt emission from high energy precipitation). The top panel shows the absolute intensity along the cut highlighted by a white line on the bottom panel. In Movie 5, a sharp boundary defining the leading edge of the patch moves at an approximately constant velocity. Once this boundary has passed the field of view, the patch exhibits pure pulsation with "on" and "off" periods of highly varying lengths, and it is also clear that the patch "fills up" and empties from a specific direction rather than turning on and off uniformly. During the longer off periods the intensity drops to the noise floor. Movie 6 shows pulsating aurora with non-pulsating substructures. During the "on" period, the patch intensity is uniform, while 
bands of non-pulsating diffuse and black substructures appear during the "off" period. The substructures slowly drifted and changed shapes.

\subsubsection{High-energy precipitation}

Typical characteristic energy of the pulsating aurora electrons is in the range from a few $\mathrm{keV}$ to $\sim 100 \mathrm{keV}$ (e.g., Bryant et al., 1975, Sandahl et al., 1981, Miyoshi et al., 2010). Since the energy is higher than discrete and diffuse aurora, the emission altitudes of the pulsating aurora is lower than other auroras (e.g., Brown, 1976, Partamies et al., 2017a).

If we consider that the characteristic energy of the pulsating aurora electrons is high, their cyclotron resonance with whistler mode chorus waves, lower-band chorus (LBC) waves especially, is a plausible candidate to cause the pitch angle scattering, while Electron Cyclotron Harmonic (ECH) waves are less likely to cause such high energy electron precipitations (e.g., Thorne et al., 2010). The relationship between LBC and the pulsating aurora has been confirmed by various authors (Nishimura et al., 2010, Jaynes et al., 2013, Miyoshi et al., 2015b). Kasahara et al. (2018) showed that the flux inside the loss cone increases simultaneously with the chorus waves by the Arase observations, and these electrons inside the loss cone correspond to the pulsating aurora on the ground. The characteristic energy of precipitating electrons depends on the magnetic local time. Hosokawa and Ogawa (2015) found that the ionization altitude, which indicates the precipitating energies of the pulsating aurora electrons, decreases in the morning side from the EISCAT observations. Oyama et al. (2017) indicated similar results.

Recently, it was found that sub-relativistic electrons precipitate into the middle atmosphere simultaneously during the pulsating aurora (Miyoshi et al., 2015a). Miyoshi et al. (2015a) proposed a model, in which wide energy electron simultaneously precipitate into the atmosphere during the pulsating aurora, if the chorus waves propagate to higher latitudes (Horne and Thorne, 2003). The Miyoshi theory showed that chorus waves can cause tens $\mathrm{keV}$ electron scattering near the magnetic equator, which contributes to the optical emissions of the pulsating aurora. And then, several chorus waves can propagate to the higher-latitude along the field line as observed by Cluster (Santolik et al., 2014), which causes the scattering of sub-relativistic and relativistic electrons due to changes of the resonance condition. The Miyoshi theory suggested that the scattered subrelativistic/relativistic electrons are observed as relativistic electron microbursts simultaneously with pulsating aurora.

This finding is important to consider the effects on the middle and upper atmosphere, because a few hundred $\mathrm{keV}$ electrons can ionize in the mesosphere and cause enhancements of $\mathrm{NO}_{\mathrm{x}}$ and $\mathrm{HO}_{\mathrm{x}}$ and resultant decrease of $\mathrm{O}_{3}$ (Turunen et al., 2016).

Considering the results expected from the Miyoshi theory, it has been postulated that the microbursts of relativistic electrons occur in association with the pulsating aurora (Miyoshi et al., 2010, Saito et al., 2012). Quasi-3 Hz modulations embedded in the main modulation of the pulsating aurora and these internal modulations are caused by each rising tone elements of chorus waves (Miyoshi et al., 2015b). The time scale of the internal modulations of the pulsating aurora is similar to or a little bit longer than the microbursts of the relativistic electrons, suggesting a close relationship between the internal modulations of the pulsating aurora and the microbursts. Recent low-altitude observations such as SAMPEX and Firebird II 
suggested scale size of tens $\mathrm{km}$, which may be the same scale size of the pulsating patch or smaller (Crew et al., 2016). It is interesting to investigate the relationship between the pulsating aurora and the microbursts of relativistic electrons, which contribute to more quantitative understanding of the pulsating aurora.

\subsubsection{Role of ECH waves}

In the inner magnetosphere $(L<\sim 8)$, diffuse aurora including pulsating aurora is mainly caused by lower-band chorus waves as demonstrated in section 1 , 2.2.3, 2.2.4. On the other hand, upper-band chorus and ECH waves can also, theoretically, scatter electrons through cyclotron resonance (e.g., Lyons et al., 1974; Ni et al., 2008) and can account for lower energy portion of precipitating particles. Miyoshi et al. (2015b) showed that a close set of upper-band chorus waves causes the stable precipitations at $\sim 1 \mathrm{keV}$, while lower-band chorus bursts cause the main modulation of more energetic electrons, and a train of rising tone elements embedded in the lower-band chorus bursts drives the internal modulations. Notwithstanding the long radiative timescale of $630.0-\mathrm{nm}$ emissions, pulsating auroral emissions at wavelength of $630.0 \mathrm{~nm}$ have been reported (Eather, 1969; Liang et al., 2016). Their generation mechanism cannot be explained by gyroresonance with lower-band chorus waves because the gyroresonance energy of lower-band chorus waves is too high to cause $630.0 \mathrm{~nm}$ emissions in the ionospheric $F$ region. Liang et al. (2016) suggested that upper-band chorus and $\mathrm{ECH}$ waves may scatter the pitch angle of low energy electrons and cause faint $630.0 \mathrm{~nm}$ pulsating aurora in addition to the $557.7 \mathrm{~nm}$ pulsating aurora. Fukizawa et al. (2018) performed a detailed event study using coordinated Arase satellite and ground-based optical observations and showed that ECH wave intensities had a positive correlation with pulsating auroral intensities whose period was a few dozen seconds, and that lower-band chorus wave intensities had correlation with pulsating auroral intensities whose period was a few seconds. It was suggested that lower-band chorus waves cause short-period pulsating aurora at low altitude, while ECH waves cause long-period pulsating aurora at high altitude.

In the outer magnetosphere $(L>\sim 8)$, the occurrence rate of moderately intense chorus emissions ( $\geq 10 \mathrm{pT}$ ) drops significantly, while moderately strong ECH emissions ( 0.1-1.0 $\mathrm{mV} / \mathrm{m}$ ) have been reported to extend up to $~ 12 R_{\mathrm{E}}$ (e.g., Roeder and Koons 1989; Ni et al., 2011, 2017). These observations suggest that ECH waves may play a leading role in driving diffuse aurora at $L>\sim 8$. Liang et al. (2011) showed that intensities of ECH waves had an unambiguous positive correlation with those of diffuse auroral precipitation using the simultaneous in-situ wave and particle observations by THEMIS satellites and ground-based NORSTAR optical auroral observations at $L=11.5$ during either an absence of chorus emissions or very weak chorus emissions. The scattering rate of central plasma sheet electrons by $\mathrm{ECH}$ waves, the subsequent ionospheric precipitation flux, and resulting auroral brightness were quantified by $\mathrm{Ni}$ et al. (2012), who concluded they were consistent with observations. ECH waves can play an important role in the outer magnetosphere to cause diffuse aurora. 


\subsubsection{Reflected and Secondary electrons}

Advances in imaging of aurora have opened up the exploration of auroral signatures to faster timescales, smaller spatial scales and, overall, scales that require wider dynamic range to enable more detailed morphological resolution. It can be said that a significant part of new insights come from such a change coupled with our ability to handle much larger volumes of data, a necessity when recording many hours a night of auroral activity. The recently observed optical signatures of inter-hemispheric electron reflections within pulsating aurora (Samara et al., 2017) are in that category. These had been inferred to be observable from prior theory and modeling work but even initial verification from optical signatures had been elusive partly because of the observational conditions needed.

Pulsating aurora is often observed against a non-pulsating background created by soft electrons (Smith et al., 1980; McEwen et al., 1981; Sandahl, 1985). This background has been identified by Evans et al. (1987), who suggest that these electrons originate from the opposite hemisphere in conjunction with simultaneously occurring pulsations there. They determine that this population arises from secondary electrons and backscattered electrons produced by the primary high energy pulsating electrons. e-POP satellite observations over pulsating aurora have also detected upgoing low-energy electrons, which are considered to be backscattered secondary electrons (Knudsen et al., 2015).

Samara et al. (2017) highlighted a case where the temporal and intensity variations of pulsating auroral are in good agreement with the predictions of the SuperThermal Electron Transport (STET) code. A pulsating aurora event was observed at Poker Flat, AK with the MOOSE imager suite in multiple fields of view but it was the very narrow field of view imager (4 degree field of view) that was operated at 56 frames per second (16 ms exposure time) with no filter that enabled the observations of the secondary electron peaks. This type of analysis is only possible with a narrow field of view and high frame rates. In the optical signatures Samara et al. (2017) identified four primary peaks and assumed that they are caused by a pitch-angle scattering mechanism in the equatorial magnetosphere, which would send electrons into both loss-cones (northern and southern hemispheres) at the same time (Nishimura et al., 2010). This would produce primary peaks in both hemispheres at the same time. As part of this process a portion of these primary electrons get scattered back up and head toward the opposite hemisphere producing the secondary peaks observed. These faint secondary pulses were visible in the data because of the high frame rate, the high signal-to-noise ratio - maximized by the white-light imaging - and the morphology of the pulsations. Specifically, the temporal characteristics of the auroral event must be such that the "pulsation-on" time is short - less than the bounce time of a few seconds - and the spacing between pulses must be larger than at least several bounce periods. The beginning of the event analyzed in Samara et al. (2017) met both of those criteria with "pulsation-on" times of $\sim 1 \mathrm{~s}$ and times between the main pulses of $6-9 \mathrm{~s}$. The spacing of the peaks ( 1.5 to $2 \mathrm{~s}$ ) corresponds to electron energies of 6-10 keV, for a field line length of $14.26 \mathrm{Re}$, which is consistent with many observations of diffuse and more specifically pulsating auroral electron precipitation.

Modeling work using STET, such as Khazanov et al. (2017), has shown that the reflected primary and secondary electrons can lead to significant changes in the precipitating electron distributions in regions of diffuse aurorae. Due to the highly time-varying nature of these processes and the short bounce periods of $1-5$ 
seconds, it has proven difficult to quantify any evidence of these reflected electrons in optical auroral observations. The Samara et al. (2017) work advanced our understanding of electron precipitation in two ways. First by offering a peak into a scale we do not often see and second by verifying predictions from consistent theoretical work. These results are consistent with the predictions of the STET model, both in terms of the production of a reflected electron population and the relative intensities of the reflected electron distributions. They are also consistent with early in-situ measurements and theoretical work suggesting that $\sim 10-20 \%$ of the precipitated electron fluxes get reflected back to the conjugate hemisphere (O’Brien, 1964; Rees, 1968).

There is a distinct variation in the reported measured electron energies associated with pulsating aurora (from a few $\mathrm{keV}$ to as high as $140 \mathrm{keV}$ ) suggesting both different generation mechanisms but also different resulting ionospheric effects. In all previous studies the secondary and backscattered electron populations that exist within the diffuse aurora have not been considered. As such the optical signatures of reflected electrons have broad implications because they highlight that the formation of the auroral electron distributions within regions of diffuse and pulsating aurora contain contributions from reflected primary and secondary electrons. These electrons, which can be the result of multiple reflections, can ultimately lead to larger fluxes than expected when considering only the primary injection of magnetospheric electrons. While they have largely been missing from the current theoretical studies of particle precipitation the inclusion of a reflected electron population which can have immediate implications for studies of magnetosphere-ionosphere coupling.

\subsubsection{Ionosphere dynamics}

The effect of pulsating aurora on the ionospheric electrodynamics (current system) has been studied extensively by using ground-based radars and satellites in the last decade. Hosokawa et al. (2008) introduced an interval of pulsating aurora during which the ionospheric electric field, as detected by a SuperDARN radar in Iceland, oscillates in close correlation with the optical pulsation. They interpreted this oscillation as a result of quasi-periodic appearance of polarization electric field generated by a modulation of electron density (i.e., conductance) due to precipitation of pulsating aurora electrons (this idea is based on an earlier study by Oguti and Hayashi, 1984)

Later, Hosokawa et al. (2010) demonstrated, by using the EISCAT radar in Troms $\varnothing$, that the electron density and Hall conductance actually changes in harmony with the optical pulsation, which implies that pulsating aurora has a potential to modulate the ionospheric current system in the quasi-periodic manner. They also directly measured similar pulsations in the northward electric field by using one of the remote site radars in Kiruna, which should be a result of quasiperiodic appearance of electric field within the patches of pulsating aurora. However, to explain the origin of electric field oscillation by the current hypothesis in a quantitative manner, we need to consider an escape of charges accumulated at the boundary of pulsating aurora patches. Based on the calculation of Hosokawa et al. (2010), about $70 \%$ of charges should escape from the edges of pulsating aurora patches. Such a significant escape of charges could be associated with field-aligned current (FAC) flowing in/out along the boundary of pulsating aurora patches

An earlier study by Fujii et al. (1985) detected such small-scale structures of FAC in the vicinity of pulsating aurora patches by using a magnetometer 
onboard the MAGSAT satellite. They indicated that FACs are actually flowing near the edges of the patches. More recently, Gillies et al. (2015) have introduced similar observations of FACs in the vicinity of pulsating aurora patches by using Swarm satellite. They identified strong downward currents just poleward and equatorward of the pulsating patches. Weaker upward currents are observed throughout the interior of the patches, leading the authors to suggest that currents might close via horizontal currents in the ionosphere. Such a FAC near the boundary is basically consistent with the model of Oguti and Hayashi (1984). The above-mentioned set of studies indicates that electric field can be modified within the patches of pulsating aurora by the local ionospheric electrodynamics. Such a change in the ionospheric electric field may modify the large-scale magnetospheric electric field only within the source region of pulsating aurora patches. This process could characterize the shape of pulsating aurora patches by determining the spatial structure of cold plasma density in the magnetosphere. Not only that, the modification of electric field by the ionospheric feedback process may introduce a difference between the apparent patch motion in the ionosphere and the motion of cold source plasma in the magnetosphere, especially when the ambient large-scale electric field is relatively small (as in the case in Humberset et al. (2018)).

The distinct difference in altitude of diffuse and pulsating aurora is important because it is indicative of the presence of two separate populations of precipitating electrons, with the higher-energy population being the pulsating one. In order to understand the relationship between diffuse and pulsating aurora, Brown et al. (1976) triangulated ground-based optical observations of diffuse and pulsating aurora from a $10 \mathrm{~km}$ baseline. This configuration provides, essentially, a measurement of the lower border of these emissions. They report that the diffuse aurora can have lower borders from $118 \mathrm{~km}$ to $375 \mathrm{~km}$ (based on 10 measurements). The median altitude of these events was near $150 \mathrm{~km}$, which imply precipitation energies of up to $\sim 1 \mathrm{keV}$. The pulsating aurora (19 measurements), however, tended to have lower borders from $82 \mathrm{~km}$ to $105 \mathrm{~km}$, with a median altitude of $92 \mathrm{~km}$, implying $10 \mathrm{keV}$ to $60 \mathrm{keV}$ electron precipitation. Their Figure 2 shows a schematic drawing illustrating the altitudinal relationship of pulsating aurora and the higher-altitude diffuse aurora in which it is embedded.

Partamies et al. (2017a) also triangulated ground-based optical measurements, an effort that included 400 intervals of pulsating aurora. They find that the peak in auroral emission height decreases by $\sim 8 \mathrm{~km}$ at the start of a pulsating aurora event, suggesting a corresponding increase in precipitating electron energy. While this result might appear to indicate a gradual transition from lower energies (with the diffuse aurora) to the higher energies of pulsating aurora, this is not the case. In fact, a distinct effort to exclude other types of aurora from this study, events were selected so that the start was when the pulsating aurora became the dominant auroral feature.

Using data from the Reimei satellite, Miyoshi et al. (2015b) showed optical observations of pulsating aurora that are well-correlated with electron measurements. They conclude that the electrons that coincide with the variations in brightness are those with energies above $3 \mathrm{keV}$ (but up to the instrument limit of $12 \mathrm{keV}$ ). Lower energy electrons are also present, with energies of $\sim 1 \mathrm{keV}$ but 
having stable signatures (i.e., producing diffuse aurora). They note a gap between these two populations, which they attribute to lower- and upper-band chorus waves. They also note that quasi-3 Hz modulation of only the higher energy portion of the electron precipitation and deem these to be driven by processes internal to the scattering mechanism.

Sandahl et al. (1980) provided a somewhat similar result. Using data from a rocket launched from the Esrange Space Center into pulsating aurora, with instrumentation to measure electron energies from near 0 to $200 \mathrm{keV}$, they found fluctuations in precipitating electron fluxes at energies above $5 \mathrm{keV}$, with a peak in energy flux at about $20 \mathrm{keV}$. Electron fluxes decrease significantly near 40 $\mathrm{keV}$, but they show that weak pulsations were observed even up to $140 \mathrm{keV}$. As Miyoshi et al. (2015b) would later show, these authors also reported a $\sim 3 \mathrm{~Hz}$ modulation, but only at higher energies, above $25 \mathrm{keV}$ in this case. Non-pulsating electrons are also measured below $5 \mathrm{keV}$, down to a few hundred $\mathrm{eV}$, but with no gap, as described by Miyoshi et al. (2015b).

\subsubsection{Ion outflow}

As explained by Strangeway et al. (2005), ion outflow $\left(\mathrm{O}^{+}\right.$ions that have acquired gravitational escape speed) is a two-step process. At lower altitudes, ion upflow can occur via one of two very different mechanisms (Wahlund et al., 1992). In Type 1 ion upflow, $\mathrm{O}^{+}$ions are heated near $110-120 \mathrm{~km}$ altitude by Joule heating, a process that can lift this population up to perhaps several hundred kilometers. In Type 2 ion upflow, precipitating soft electrons collide with and heat ambient ionospheric electrons which then expand upwards adiabatically, thereby creating an ambipolar electric field that lifts the $\mathrm{O}^{+}$ions to altitudes of several hundred kilometers. In either case, once the $\mathrm{O}^{+}$ions are at these higher altitudes, they may be further energized by ambient waves that can accelerate them to escape velocity (then called ion outflow). If this secondary process does not develop, the ions will drift back downward to the ionosphere.

This process is most prevalent in the cusp region, where intense Joule heating and Alfvènic aurora (i.e., soft precipitation) are common. One would not expect to find ion upwelling in pulsating aurora because of the apparent lack of such processes in these cases, although the recent results described in the previous section may indicate otherwise.

Liang et al. (2015) sought to determine what processes define the shape and size of patches and highlighted a number of theories suggesting that flux tubes above the patches must contain enhanced cold plasma that determine the structure. These authors further suggested that ion outflow could provide the requisite cold plasma, though no observations of upflow were presented in that paper. Evidence of PFISR observations of ion upflow (not outflow) over pulsating aurora are presented by Liang et al. (2018), which they attribute to the deposition of heat flux from higher altitudes that lead to the formation of an ambipolar field and subsequent ion upflow. 
Kenward et al. (2019) also used PFISR observations, in conjunction with allsky imagers filtered at 557.7 and $630.0 \mathrm{~nm}$ and were able to show that the soft precipitation directly heated the electron population in the F-region. This heated population led to the formation of an observed ambipolar field, its resulting parallel electric field and the associated upflow. Still, as these authors point out, the upflow speeds are well below escape speeds (near $450 \mathrm{~km}$ altitude, where the data are acquired) and the question of whether a secondary process exists at higher altitudes that would further energize these ions is an open one.

\subsubsection{Coupling to the thermosphere}

In this section, coupling of pulsating aurora to the thermosphere is addressed via a discussion of four disparate papers. Wilson et al. (2005) used an infrasonic array of 8 microphones to record acoustic pulses driven by pulsating aurora. They conclude that the acoustic pulses result from ionospheric heating due to the precipitating electron population, which then couples to the thermosphere to launch downward pulses. They show that their signatures originate from sources within $35 \mathrm{~km}$ of the zenith above the array (assuming a source height of $110 \mathrm{~km}$ ).

Oyama et al. (2010) used data from a Fabry-Perot Interferometer (FPI) and an all-sky imager (both at a wavelength of $557.7 \mathrm{~nm}$ ), as well as the EISCAT UHF radar, to study thermospheric winds in pulsating aurora. They found that in pulsating aurora, when convection electric fields were smaller than $15 \mathrm{mV} / \mathrm{m}$, wind fluctuations were then isolated at the edges and/or in the darker areas of auroral patches. The largest vertical amplitudes they observed were up to $20 \mathrm{~m} / \mathrm{s}$, suggesting that the wind fluctuations were localized to the patches.

In terms of atmospheric effects of pulsating aurora, Takahashi et al. (2017) followed up on an earlier report by Tsuda et al. (2013) that described a decrease in mesospheric sodium in conjunction with pulsating aurora. Takahashi et al. (2017) examined data from a single event over Troms $\varnothing$, Norway, observed using an all-sky imager and EISCAT Troms $\emptyset$ radar, with the radar showing enhanced ionization below $100 \mathrm{~km}$. Simultaneous observations by the sodium lidar at Troms $\varnothing$ showed sodium depletions at those altitudes of 5-8\%, lasting 8 minutes. Based on model results, the sequence they describe begins with pulsating auroral electron ionization producing $\mathrm{N}_{2}{ }^{+}$and $\mathrm{O}_{2}{ }^{+}$, followed quickly by the transition of

$\mathrm{N}_{2}{ }^{+}$to $\mathrm{NO}^{+}$. The environment of $\mathrm{NO}^{+}$and $\mathrm{O}_{2}{ }^{+}$ultimately leads to the depletion of sodium via charge transfer reactions with these ions.

An entirely different atmospheric impact is described by Turunen et al. (2016), who sought to quantify the role of pulsating auroral electrons on ozone depletion, noting that the energetic precipitation produces odd nitrogen and odd hydrogen. Through catalytic reaction chains, these populations drive the ozone depletion either at the high altitudes where the initial ionization occurs, or at lower altitudes following transport of these populations. In their paper, they consider a single event that included $>200 \mathrm{keV}$ electron precipitation that led to model results showing depletion of odd oxygen by several tens of a percent. 


\section{Numerical simulation}

\subsection{Wave-particle interaction, chorus/ECH generation, scattering}

Wave-particle interactions cause the pitch angle scattering of energetic particles in the magnetosphere, resulting in diffuse/pulsating aurora. Among a variety of wave modes in the magnetospheric plasma, whistler-mode waves play dominant roles in the pitch angle scattering of energetic electrons. Whistler-mode chorus emissions are typical example of whistler-mode waves in the magnetosphere. Chorus emissions are coherent electromagnetic waves observed mainly in the dawn side of the magnetosphere, characterized by their spectral features showing rising/falling tones and by the periodic generation of wave elements in the time scale closely related to pulsating aurora. Understanding of the chorus generation mechanism is essential for the thorough understanding of the mechanism controlling the periodicity of pulsating aurora.

The theory of the whistler-mode chorus generation has been substantially advanced since 2000's, based on the development of the nonlinear wave growth theory by Omura et al. $(2008,2009)$ supported by results of numerical experiments (Katoh and Omura, 2007, Hikishima et al., 2009). By an electron hybrid code simulation in a spatially one-dimensional simulation system along a field line of the dipole field, Katoh and Omura (2007) reproduced that coherent wave elements with rising tones are emerged from a band of whistler-mode waves around the magnetic equator. Hikishima et al. (2009) also reproduced the whistler-mode chorus generation in the equatorial region by a plasma full particle code. Omura et al. $(2008,2009)$ proposed the nonlinear wave growth theory for the chorus generation from the magnetic equator.

The theory and simulation suggest that the generation process of chorus can be categorized into (1) linear phase and (2) non-linear phase. Under the presence of energetic electrons having a temperature anisotropy of the velocity distribution function, a band of whistler-mode waves is generated around the magnetic equator. The time scale of the wave growth can be estimated by the growth rate of waves based on the linear theory (e.g., Kennel and Petschek, 1966; Summers et al., 2013). As the wave amplitude grows, a coherent whistler-mode wave appears from a band of waves, and then nonlinear effects become significant on the motion of resonant electrons. Thereby the wave generation process undergoes the non-linear phase.

Omura et al. (2008) suggested that an electromagnetic electron hole will be formed in the velocity phase space through nonlinear wave-particle interactions in the equatorial region of the magnetosphere. They also suggested that the most of resonant electrons will be untrapped from a coherent whistler-mode wave and that nonlinear trajectories of resonant untrapped electrons result in the formation of nonlinear resonant currents. Based on the nonlinear wave growth theory, the threshold amplitude required for the chorus generation has been proposed (Omura et al., 2009). A series of electron hybrid code simulations have been performed for different number density of energetic electrons (Katoh and Omura, 2011), for 
different spatial gradient of the background magnetic field (Katoh and Omura, 2013), and for different temperature anisotropy of energetic electrons at the magnetic equator (Katoh et al., 2018). Results of the simulations revealed that distinct chorus with rising tones appeared when the wave amplitude of a band of whistler-mode waves exceeds the theoretically estimated threshold amplitude. Simulation results in Katoh and Omura (2011) also revealed that the frequency sweep rate becomes high for large wave amplitude of chorus elements, as predicted by Omura et al. (2009). The proposed nonlinear wave growth theory well explains not only simulation results but also satellite observation. Kurita et al. (2012) analyzed THEMIS data of chorus elements without a gap at half the gyrofrequency. They showed that frequency profiles of the wave amplitudes of the chorus elements are well explained by the optimum wave amplitude proposed by Omura and Nunn (2011). Hikishima et al. (2010) revealed by a plasma full particle code simulation that microburst precipitation of 10-100 keV electrons accompanies the generation of discrete chorus emissions.

There are many reports from the low-altitude satellites and sounding rocket experiments that the precipitating electrons have clear energy dispersions, which have been used for the time-of-flight analysis to estimate the modulation region of the pulsating aurora. Miyoshi et al. (2010) proposed a model for the modulations of the pulsating aurora electrons, including the effect of the propagation of the chorus waves along the field line. They derived the theoretical curve of energy dispersion for precipitating electrons. The theoretical energy dispersion is fitted with the observed energy dispersion to estimate parameters of chorus waves. Later, Saito et al. (2012) extended this theoretical energy dispersion including relativistic effects.

More recently, Miyoshi et al. (2015b) conducted the GEMSIS-RBW testparticle simulations (Saito et al., 2012) to calculate cyclotron resonance between upper- and lower-band chorus waves and electrons bounced along the field line. In general, lower-band chorus bursts every a few seconds include a few rising tone elements, while continuous upper-band chorus include continuous elements. There is a half-gyro frequency gap between lower-band and upper-band chorus waves. As shown in Figure 5, burst precipitations more than a few $\mathrm{keV}$ are observed with energy dispersion. Besides the burst precipitations, stable precipitations are found around $1 \mathrm{keV}$. From investigations of the simulation, the burst precipitations are caused by the lower-band chorus waves, while the stable precipitations are driven by the upper-band chorus waves. There is a precipitation gap between the burst precipitations and the stable precipitations, which corresponds to the resonance energy of the half-gyro frequency gap. Characteristics of energy spectrum of precipitating electrons are well consistent with the energy spectrum measured by the low-altitude satellite (Miyoshi et al., 2010, 2015b, Nishiyama et al., 2011). The study indicates that the origin of the internal modulations of the pulsating aurora is the train of the rising tone elements, while the main modulations is the lower-band chorus bursts. These relationships are confirmed by satellite-ground based conjugate observations; main modulations and chorus bursts: Nishimura et al. (2010), Kasahara et al.(2018), internal modulations and rising tone elements: Ozaki et al. (2018). Also, the background emissions of the pulsating aurora (Evans et al., 1987) is caused by the upper-band chorus waves.

It is interesting to note the possibility of tens $\mathrm{keV}$ and sub-relativistic/relativistic electron precipitations associated with the pulsating aurora. Miyoshi et al. (2010, 2015a) proposed a model that chorus waves propagating along the field line cause wide-energy electron precipitations from a few $\mathrm{keV}$ to multi-hundred $\mathrm{keV}$ and 
$\mathrm{MeV}$ electrons if chorus waves propagate to the higher latitudes, and they suggested that precipitations of multi-hundred $\mathrm{keV}$ and $\mathrm{MeV}$ electron simultaneously occur during the pulsating aurora. The theoretical energy dispersion curve derived from Saito et al. (2012) that includes precipitations from a few $\mathrm{keV}$ to more than $\mathrm{MeV}$ can be used to compare with the future observations on precipitating electrons for wide energy electrons associated with the pulsating aurora.

As we have mentioned in Section2, ECH waves are another candidate to cause the pitch angle scattering to cause diffuse aurora (Ni et al., 2012, Zhang et al., 2015) and pulsating aurora (Liang et al., 2010). Ni et al.(2012) estimated scattering rate of electrons by ECH waves and claimed that ECH waves can play an important role to cause the diffuse aurora in higher L-shell region. Several studies estimated linear growth rate of ECH waves (Ashour-Abdalla and Kennel, 1978, Zhou et al., 2017, Liu et al., 2018), and Zhou et al.[2017] and Liu et al.[2018] concluded that the loss-cone distribution should be a free energy source to drive ECH waves. Detail distribution function data have been observed by Van Allen Probes (e.g., Zhou et al., 2017) and Arase (Kazama et al., 2018) in the inner magnetosphere, comparisons between in-situ particle/wave observations and ground-based optical measurements are useful to identity generation of ECH waves and scattering of electrons.

\subsection{Spatial extent, modulation}

The size of pulsating aurora patches has been explained by the spatial scale of wave-particle interactions occurring in the equatorial region of the magnetosphere. Demekhov and Trakhtengerts (1994) proposed a flow cyclotron maser model as a mechanism controlling both temporal and spatial scale of pulsating aurora. Assuming a plasma duct formed along a field line as a region where efficient waveparticle interaction occurs, they proposed that the pulsation 'on' time of pulsating patches corresponds to the duration of interactions in the duct and that the pulsating 'off' time is the time interval restoring free energy inside the duct through the transportation of energetic electrons. The modulation of auroral brightness inside the patch has been explained by the repetition period of individual chorus elements. The size of the duct has been related to the spatial structure of ambient plasma. Katoh (2014) performed a simulation study of the propagation of whistler-mode waves in the meridional plane of the inner magnetosphere. While the simulation results showed that the duct is formed by either enhancement or depletion of plasma density, the propagation property of waves inside the duct becomes different depending on the plasma density structure. The propagation property should affect the spatial modulation of auroral emissions inside pulsating patches.

\subsection{Modeling parameters, consistency with observation}

Recent development of computational resources enables us to perform numerical experiments with realistic initial conditions as we observe in the magnetosphere. 
A self-consistent simulation of the whistler-mode chorus generation was performed in Katoh and Omura (2016) with the real spatial scale of the inner magnetosphere. They showed that the spectral properties of reproduced chorus elements are consistent with those observed by the Cluster spacecraft (Santolik et al., 2003). The consistency between the simulation and satellite observation has also been performed in Demekhov et al. (2016).

(a)

chorus waves at the magnetic equator
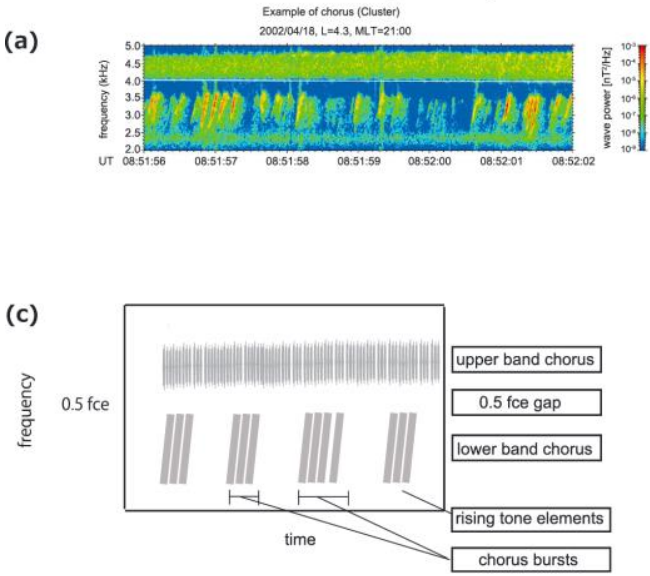

chorus waves at the magnetic equator

- lower band chorus

- chorus bursts

- rising tone elements

- upper band chorus

- 0.5 fce gap electron precipitaions at ionosphere

(b)

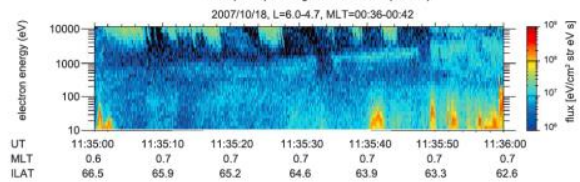

(d)

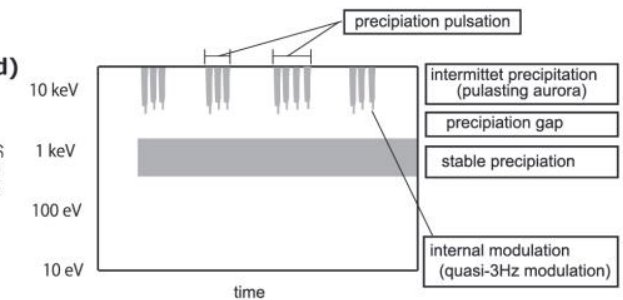

pulsating aurora

- pulsating aurora

- ON - OFF pulsation

- internal modulations (quasi-3 $\mathrm{Hz}$ modulation)

- stable precipiation $(\sim 1 \mathrm{keV})$

- precipiatoin gap

Figure 5 (a) Example of chorus frequency spectrum observed by the Cluster satellite. (b)

Example of pulsating aurora energy spectrum observed by the Reimei satellite. (c and d)

Schematic diagram to indicate the correspondences between the frequency spectrum of chorus waves and energy spectrum of precipitating electrons for the pulsating aurora, together with typical frequency-time spectrogram of chorus waves and energy-time diagram of precipitating electrons for the pulsating aurora (Miyoshi et al., 2015b). 


\section{Summary and open questions}

This chapter reviewed fundamental properties of diffuse and pulsating aurora. Section 1 summarized the definition, the large-scale morphology, types of pulsation, and driving process of diffuse/pulsating aurora. Section 2 reviewed recent advances. Section 2.1 covered observation techniques, Section 2.2 presented recent findings on occurrence, duration, altitude, evolution, small-scale structures, fast modulation, relation to high-energy precipitation, the role of ECH waves, reflected and secondary electrons, and ionosphere dynamics. Section 3 reviewed recent advances in simulation of wave-particle interaction.

Despite that major advances have been made in recent years, the community still faces outstanding questions on fundamental properties of diffuse and pulsating aurora as listed below:

- Origin of chorus modulation. Although the auroral pulsation has been found to originate in chorus modulation, it is still an open question what controls chorus modulation. Density modulation and non-linear processes have been suggested but no definitive conclusion has been made. Since whistler-mode waves in the plasma sheet do not always exhibit rising tones but also show falling tones or unstructured emission. Those different types of wave generation processes need to be investigated for understanding pulsating auroral modulation.

- Pulsating auroral patch size. The size of pulsating auroral patches reflect the size of coherent chorus size. This is also likely true of substructures of pulsating chorus and elements of chorus waves. However, it is unclear what determines the size of coherent chorus waves. It is much larger than electron gyroradius or chorus perpendicular wavelength, and thus collective processes beyond the electron scale are expected to play a role.

- Origin of fine-scale diffuse aurora including substructures. Diffuse aurora is not a structureless feature but involves fine-scale substructures. One fundamentally important issue has to do with the persistence of the shapes of pulsating patches that sustain over several minutes, even in cases where the patches appear to have disappeared but then reappeared. Although ideas such as pressure-driven processes have been proposed, it is not understood how such structures form in the magnetosphere and what determines the size and modulation. Since it is difficult to have satellite conjunctions with fine-scale aurora, knowledge of such structures has been severely limited. The implicit question is whether the precipitation source (i.e., near the equatorial region) or the ionosphere itself is responsible for the shape of patches. In the latter case where, for example, ionospheric conductivity plays a role, the question would then become how this might contribute to a feedback process.

- A related question is what determines the propagation speed of patches. Again, the answer may indicate that the ionosphere is intricately linked to the patches (i.e., if the patches are tied to convection), or may suggest that patches are simply signatures of source region dynamics.

- Role of ECH waves and upper-band chorus. While lower-band chorus has been identified as the dominant source of waves for pitch angle scattering, ECH waves and upper-band chorus have also been associated with pulsating aurora. A thorough study is desired to find the probability and conditions that those wave modes become important. Also the role of parallel potential drop and secondary electrons should also be investigated. 
Acknowledgements. The work of Y.N. was supported by NASA grant NNX17AL22G and 80NSSC18K0657, NSF grants PLR-1341359, AGS-1737823, and AFOSR FA9559-16-1-0364. The work by NP was supported by the Research Council of Norway under CoE contract 223252. Y.K., Y.M., and K.H. are supported by JSPS Kakenhi (15H05747). Y.K, and Y.M are supported by JSPS Kakenhi (15H05815). Y.M is supported by JSPS Kakenhi (16H06286). Y.K., Y.M., and K.H. are supported by the International Space Science Institutes Beijing (ISSI-BJ) International Team program. The work of NS was supported by NASA Earth \& Space Science Fellowship Program grant 80NSSC17K0433. The THEMIS mission and all-sky imagers are supported by NASA contract NAS5-02099, CSA contract 9F007-046101 and NSF grant AGS-1004736. ML was supported by NASA grant 80NSSC18K0950. DKW was supported by the Natural Environment Research Council (NERC) of the UK under grant NE/N004051/1. The PWING imager was installed and operated by the pulsating aurora project (http://www.psa-research.org) and PWING project (http://www.isee.nagoya-u.ac.jp/dimr/PWING/en/). 


\section{References}

Akasofu, S. I. (1968), Polar and Magnetospheric Substorms, p. 223, D. Reidel, Dordrecht, Holland.

Axelsson, K., Sergienko, T., Nilsson, H., Brändstrm, U., Ebihara, Y., Asamura, K., \& Hirahara, M. (2012). Spatial characteristics of wave-like structures in diffuse aurora obtained using optical observations. Annales Geophysicae, 30(12), 1693-1701. https://doi.org/10.5194/angeo-30-1693-2012

Arnoldy, R. L., Dragoon, K., Cahill, L. J., Mende, S. B., \& Rosenberg, T. J. (1982). Detailed correlations of magnetic field and riometer observations at $L=4.2$ with pulsating aurora. Journal of Geophysical Research, 87(A12), 10449. https://doi.org/10.1029/JA087iA12p10449.

Ashour-Abdalla, M., and C. Kennel (1978), Nonconvective and convective electron cyclotron harmonic instabilities,J. Geophys. Res.,83,1531-1543, https://doi.org/10.1029/JA083iA04p01531

Berkey, F. T. (1978), Observations of pulsating aurora in the day sector auroral zone, Planet. Space Sci., 26, 635-650.

Berkey, F. T., Anger, C. D., Akasofu, S.-I., \& Rieger, E. P. (1980). The signature of large-scale auroral structure in radio wave absorption. Journal of Geophysical Research, 85(A2), 593. https://doi.org/10.1029/JA085iA02p00593

Bland, E. C., Heino, E., Kosch, M. J., \& Partamies, N. (2018). SuperDARN RadarDerived HF Radio Attenuation During the September 2017 Solar Proton Events. Space Weather, 16(10), 1455-1469. https://doi.org/10.1029/2018SW001916

Bland, E. C., Partamies, N., Heino, E., Yukimatu, A. S., \& Miyaoka, H. (2019). Energetic electron precipitation occurrence rates determined using the Syowa East SuperDARN radar. Journal of Geophysical Research: Space Physics, 124. https://doi.org/10.1029/2018JA026437

Brekke, A., and H. Pettersen (1971), Some observations of pulsating aurora at Spitzbergen, Planet Space Sci, 19, 536540.

Brown, N. B., T. N. Davis, T. J. Hallinan, and H. C. Stenbaek-Nielsen (1976), Altitude of pulsating aurora determined by a new instrumental technique, Geophys. Res. Lett., 3, 403-404, doi:10.1029/GL003i007p00403.

Bryant, D., Courtier, G., \& Johnstone, A. (1969). Modulation of auroral electrons at large distances from the Earth. Journal of Atmospheric and Terrestrial Physics, 31(4), 579-592. https://doi.org/10.1016/0021-9169(69)90010-5

Bryant, D., M. J. Smith, and G. M. Courtier (1975), Distant modulation of electron intensity during the expansion phase of an auroral substorm, Planet. Space Sci., 23, 867, https://doi.org/10.1016/0032-0633(75)90022-7.

Brändström U. (2003), The Auroral Large Imaging System - Design, Operation and Scientific Results, IRF Scientific Report 279, Kiruna.

Clausen, L. B. N., \& Nickisch, H. (2018). Automatic Classification of Auroral Images From the Oslo Auroral THEMIS (OATH) Data Set Using Machine Learning. Journal of Geophysical Research: Space Physics, 123(7), 56405647. https://doi.org/10.1029/2018JA025274

Comberiate, J. M., Kamalabadi, F., \& Paxton, L. J. (2007). A tomographic model for ionospheric imaging with the Global Ultraviolet Imager. Radio Science, 42(2). https://doi.org/10.1029/2005RS003348

Craven, M. and Burns, G. B. (1990), High Latitude Pulsating Aurora, Geophys. Res. Lett., VOL. 17, NO. 9, PAGES 1251-1254

Creutzberg, F., R. Gattinger, F. Harris, and A. Vallance Jones (1981), Pulsating 
auroras in relation to proton and electron auroras, Canadian Journal of Physics, 59, 1124-1130.

Crew, A. B., H. E. Spence, J. B. Blake, D. M. Lumpar, B. A. Larsen, T. P. O’Brien, S. Driscoll, M. Handley, J. Legere, S. Longworth, K. Mashburn, E. Mosleh, N. Ryhajlo, S. Smith, L. Springer, and M. Widholm (2016), First multipoint in situ observations of electron microbursts: Initial results from the NSF FIREBIRD II mission, J. Geophys. Res., 121, 5272-5283, doi:10.1002/2016JA022485.

Dahlgren, H., N. Ivchenko, J. Sullivan, B. S. Lanchester, G. Marklund, and D. Whiter (2008), Morphology and dynamics of aurora at fine scale: first results from the ASK instrument, Ann. Geophys., 26, 1041-1048, doi:10.5194/angeo26-1041-2008

Dahlgren, H., Ivchenko, N., \& Lanchester, B. S. (2012). Monoenergetic highenergy electron precipitation in thin auroral filaments. Geophysical Research Letters, 39(20). https://doi.org/10.1029/2012GL053466

Dahlgren, H., B. S. Lanchester, N. Ivchenko, and D. K. Whiter (2016), Electrodynamics and energy characteristics of aurora at high resolution by optical methods, J. Geophys. Res., 121, 6, 5966-5974, doi:10.1002/2016JA022446

Dahlgren H., B. S. Lanchester, N. Ivchenko, and D. K. Whiter (2017), Variations in energy, flux, and brightness of pulsating aurora measured at high time resolution. Annales Geophysicae, 35(3):493-503. doi: 10.5194/angeo-35493-2017. URL https://www.ann-geophys.net/35/493/2017/.

Deehr, C., \& Lummerzheim, D. (2001). Ground-based optical observations of hydrogen emission in the auroral substorm. Journal of Geophysical Research: Space Physics, 106(A1), 33-44. https://doi.org/10.1029/2000JA002010

Demekhov, A. G., and V. Y. Trakhtengerts (1994), A mechanism of formation of pulsating aurorae, J. Geophys. Res., 99(A4), 5831-5841, doi:10.1029/93JA01804.

Demekhov, A. G., U. Taubenschuss, and O. Santolik (2016), Simulation of VLF chorus emissions in the magnetosphere and comparison with THEMIS spacecraft data, J. Geophys. Res. Space Physics, 122, doi:10.1002/2016JA023057.

Donovan, E. F., Jackel, B. J., Voronkov, I., Sotirelis, T., Creutzberg, F., \& Nicholson, N. A. (2003). Ground-based optical determination of the b2i boundary: A basis for an optical MT-index. Journal of Geophysical Research (Space Physics), 108 (A3), 1115. doi: 10.1029/2001JA009198

E. Donovan, S. Mende, B. Jackel, H. Frey, M. Syrjasuo, I. Voronkov, T. Trondsen, L. Peticolas, V. Angelopoulos, S. Harris, M. Green, and M. Connors. The THEMIS all-sky imaging array -- system design and initial results from the prototype imager. Journal of Atmospheric and Solar-Terrestrial Physics, 68:1472\{1487, September 2006. doi: 10.1016/j.jastp.2005.03.027.

Duncan, C. N., F. Creutzberg, R. L. Gattinger, F. R. Harris, and A. Vallance Jones (1981), Latitudinal and temporal characteristics of pulsating auroras, Canadian Journal of Physics , 59 , 1063-1069.

Eather, R. H. (1969). Short-period auroral pulsations in $\lambda 6300$ OI. Journal of Geophysical Research, 74(21), 4998-5004. https://doi.org/10.1029/JA074i021p04998

Ebihara, Y., Sakanoi, T., Asamura, K., Hirahara, M., \& Thomsen, M. F. (2010). Reimei observation of highly structured auroras caused by nonaccelerated 
electrons. Journal of Geophysical Research: Space Physics, 115(A8), n/a-n/a. https://doi.org/10.1029/2009JA015009

Enell, C.-F., Gustavsson, B., Brändström, B. U. E., Sergienko, T. I., Verronen, P. T., Rydesäter, P., \& Sandahl, I. (2012). Tomography-like retrieval of auroral volume emission ratios for the 31 January 2008 Hotel Payload 2 event. Geoscientific Instrumentation, Methods and Data Systems Discussions, 2(1), 1-21. https://doi.org/10.5194/gid-2-1-2012

Evans, D. S., Davidson, G. T., Voss, H. D., Imhof, W. L., Mobilia, J., \& Chiu, Y. T. (1987). Interpretation of electron spectra in morningside pulsating aurorae. Journal of Geophysical Research, 92(A11), 12295. https://doi.org/10.1029/JA092iA11p12295

Fang, X., Randall, C. E., Lummerzheim, D., Wang, W., Lu, G., Solomon, S. C., \& Frahm, R. A. (2010). Parameterization of monoenergetic electron impact ionization. Geophysical Research Letters, 37(22), n/a-n/a. https://doi.org/10.1029/2010GL045406

Fritz, B. A., M. L. Lessard, M. J. Blandin and P. A. Fernandes (2015), Structure of black aurora associated with pulsating aurora, J. Geophys. Res.Space Physics, 120, 10,096-10,106, doi:10.1002/2015JA021397.

Fukizawa, M., Sakanoi, T., Miyoshi, Y., Hosokawa, K., Shiokawa, K., Katoh, Y., et al. (2018). Electrostatic electron cyclotron harmonic waves as a candidate to cause pulsating auroras. Geophysical Research Letters, 45, 12,661-12,668. https://doi.org/10.1029/2018GL080145

Fukuda, Y., R. Kataoka, Y. Miyoshi, Y. Katoh, T. Nishiyama, K. Shiokawa, Y. Ebihara, D. Hampton, and N. Iwagami (2016), Quasi-periodic rapid motion of pulsating auroras. Polar Science, 10:183-191. doi: 10.1016/j.polar.2016.03.005.

Fujii, R., T. Oguti, and T. Yamamoto (1985), Relationships between pulsating auroras and field-aligned electric currents, Mem. Natl. Inst. Polar Res., 36, 95-103.

Fujii, R., N. Sato, T. Ono, H. Fukunishi, T. Hirasawa, S. Kokubun, T. Araki, and T. Saemundsson (1987), Conjugacies of pulsating auroras by all-sky TV observations, Geophys. Res. Lett., 14, 115-118.

Gillies, D. M., D. Knudsen, E. Spanswick, E. Donovan, J. Burchill, and M. Patrick (2015), Swarm observations of field-aligned currents associated with pulsating auroral patches, J. Geophys. Res. Space Physics, 120, 9484-9499, doi:10.1002/2015JA021416.

Grandin, M., A. Kero, N. Partamies, D. McKay, D. Whiter, A. Kozlovsky, and Y. Miyoshi (2017), Observation of pulsating aurora signatures in cosmic noise absorption data. Geophysical Research Letters, 44:5292-5300. doi: 10.1002/2017GL073901.

Grono, E., Donovan, E., \& Murphy, K. R. (2017). Tracking patchy pulsating aurora through all-sky images. Annales Geophysicae, 35(4), 777-784. https://doi.org/10.5194/angeo-35-777-2017

Grono, E. and E. Donovan (2018). Differentiating diffuse auroras based on phenomenology. Annales Geophysicae, 36(3):891-898. doi: 10.5194/angeo-36-891-2018.

Grono, E. and Donovan, E. (2019), Constraining the Source Regions of Pulsating Auroras, Geophysical Research Letters, 46. doi: 10.1029/2019GL084611.

Grubbs, G., R. Michell, M. Samara, D. Hampton, and J.-M. Jahn (2018), Predicting Electron Population Characteristics in 2-D Using Multispectral Ground-Based Imaging, Geophys. Res. Lett., 45, 15-20, doi: 10.1002/2017GL075873. 
Han, D.-S., Li, J.-X., Nishimura, Y., Lyons, L. R., Bortnik, J., Zhou, M., ... Pollock, C. J. (2017). Coordinated observations of two types of diffuse auroras near magnetic local noon by Magnetospheric Multiscale mission and ground all-sky camera. Geophysical Research Letters, 44(16), 8130-8139. https://doi.org/10.1002/2017GL074447

Han, D.-S., Chen, X.-C., Liu, J.-J., Qiu, Q., Keika, K., Hu, Z.-J., ... Yang, H.-G. (2015). An extensive survey of dayside diffuse aurora based on optical observations at Yellow River Station. Journal of Geophysical Research: Space Physics, 120(9), 7447-7465. https://doi.org/10.1002/2015JA021699

Henderson, M. G. (2012), Auroral Substorms, Poleward Boundary Activations, Auroral Streamers, Omega Bands, and Onset Precursor Activity, in Auroral Phenomenology and Magnetospheric Processes: Earth and Other Planets, Geophysical Monograph Series 197, American Geophysical Union. doi: 10.1029/2011GM001165

Hikishima, M., S. Yagitani, Y. Omura, and I. Nagano (2009), Full particle simulation of whistler-mode rising chorus emissions in the magnetosphere, J. Geophys. Res., 114, A01203, doi:10.1029/2008JA013625.

Hikishima, M., Y. Omura, and D. Summers (2010), Microburst precipitation of energetic electrons associated with chorus wave generation, Geophys. Res. Lett., 37, L07103, doi:10.1029/2010GL042678.

Horne, R. B., and R. M. Thorne (2003), Relativistic electron acceleration and precipiation during resonant interactions with whistler-mode chorus, Geophys. Res. Lett., 30, 1527, doi:10.1029/2003GL016973.

Honary, F., Marple, S. R., Barratt, K., Chapman, P., Grill, M., \& Nielsen, E. (2011). Invited Article: Digital beam-forming imaging riometer systems. Review of Scientific Instruments, 82(3), 031301. https://doi.org/10.1063/1.3567309

Hosokawa, K., A. Kadokura, N. Sato, S. E. Milan, M. Lester, G. Bjornsson, and T. Saemundsson (2008), Electric field modulation behind pulsating aurora, J. Geophys. Res., 113, A11322, doi:10.1029/2008JA013601.

Hosokawa, K., Ogawa, Y., Kadokura, A., Miyaoka, H., \& Sato, N. (2010). Modulation of ionospheric conductance and electric field associated with pulsating aurora. Journal of Geophysical Research: Space Physics, 115(A3), n/a-n/a. https://doi.org/10.1029/2009JA014683

Hosokawa, K. and Y. Ogawa (2015), Ionospheric variation during pulsating aurora. Journal of Geophysical Research (Space Physics), 120:5943-5957. doi: 10.1002/2015JA021401.

Humberset, B. K., J. W. Gjerloev, M. Samara, R. G. Michell, and I. R. Mann (2016). Temporal characteristics and energy deposition of pulsating auroral patches. Journal of Geophysical Research (Space Physics), 121: 7087-7107. doi: 10.1002/2016JA022921.

Humberset, B. K., J. W. Gjerloev, I. R. Mann, R. G. Michell, and M. Samara (2018) On the Persistent Shape and Coherence of Pulsating Auroral Patches. Journal of Geophysical Research (Space Physics), 123:4272-4289. doi: 10.1029/2017JA024405.

Jackel B. J., F. Creutzberg, E. F. Donovan, and L. L. Cogger (2003). Triangulation of Auroral Red-Line Emission Heights. In K. U. Kaila, J. R. T. Jussila, and H. Holma, editors, Proceedings of the 28th Annual European Meeting on Atmospheric Studies by Optical Methods, volume 92, pages 97-100, Oulu, Finland. Sodankyla Geophysical Observatory Publications.

Jaynes, A. N., M. R. Lessard, J. V. Rodriguez, E. Donovan, T. M. Loto'aniu, and 
K. Rychert (2013), Pulsating aurora electron flux modulations in the equatorial magnetosphere, 118, 4884-4894, doi:10.1002/jgra.50434.

Jaynes, A. N., et al. (2015), Correlated Pc4-5 ULF waves, whistler-mode chorus and pulsating aurora observed by the Van Allen Probes and ground-based systems, J. Geophys. Res. Space Physics, 120, 8749-8761, doi:10.1002/2015JA021380.

Johnstone, A. D. (1978). Pulsating aurora. Nature, 274, 119-126.

Johnston, S. F. (1989). Autonomous Meridian Scanning Photometer For Auroral Observations. Optical Engineering, 28(1), 280120. https://doi.org/10.1117/12.7976895

Jones S. L., M. R. Lessard, P. A. Fernandes, D. Lummerzheim, J. L. Semeter, C. J. Heinselman, K. A. Lynch, G. Michell, P. M. Kintner, H. C. StenbaekNielsen, and K. Asamura (2009), PFISR and ROPA observations of pulsating aurora. Journal of Atmospheric and Solar-Terrestrial Physics, 71:708-716. doi: $10.1016 /$ j.jastp.2008.10.004.

Jones, S. L., M. R. Lessard, K. Rychert, E. Spanswick, and E. Donovan (2011), Large-scale aspects and temporal evolution of pulsating aurora. Journal of Geophysical Research (Space Physics), 116:A03214. doi: 10.1029/2010ja015840.

Jones, S. L., Lessard, M. R., Rychert, K., Spanswick, E., Donovan, E., \& Jaynes, A. N. (2013). Persistent, widespread pulsating aurora: A case study. Journal of Geophysical Research: Space Physics, 118, 2998-3006. https://doi.org/10.1002/jgra.50301

Kasahara, S., Miyoshi, Y., Yokota, S., Mitani, T., Kasahara, Y., Matsuda, S., ... Shinohara, I. (2018). Pulsating aurora from electron scattering by chorus waves. Nature, 554(7692), 337-340. https://doi.org/10.1038/nature25505

Kataoka, R., Y. Miyoshi, D. Hampton, T. Ishii, and H. Kozako (2012). Pulsating aurora beyond the ultra-low-frequency range.

Journal of Geo- physical Research: Space Physics, 117(A8). doi: 10.1029/2012JA017987. https://agupubs.onlinelibrary.wiley.com/doi/abs/10.1029/2012JA017987.

Kataoka, R., T. Nishiyama, Y. Tanaka, A. Kadokura, H. A. Uchida, Y. Ebihara, M. K. Ejiri, Y. Tomikawa, M. Tsutsumi, K. Sato, Y. Miyoshi, K. Shiokawa, S. Kurita, Y. Kasahara, M. Ozaki, K. Hosokawa, S. Matsuda, I. Shinohara, T. Takashima, T. Sato, T. Mitani, T. Hori and N. Higashio (2019), Transient ionization of the mesosphere during auroral breakup: Arase satellite and ground-based conjugate observations at Syowa Station, Earth, Planets and Space, 71:9 https://doi.org/10.1186/s40623-019-0989-7

Kataoka, R., Y. Miyoshi, K. Shigematsu, D. Hampton, Y. Mori, T. Kubo, A. Yamashita, M. Tanaka, T. Taka- hei, T. Nakai, H. Miyahara, and K. Shiokawa (2013). Stereoscopic determination of all-sky altitude map of au- rora using two ground-based Nikon DSLR cameras. Annales Geophysicae, 31(9):15431548. doi: 10.5194/angeo-31-1543-2013. URL https://www.anngeophys.net/31/1543/2013/.

Kataoka, R., Fukuda, Y., Uchida, H. A., Yamada, H., Miyoshi, Y., Ebihara, Y., Hampton, D. (2016). High-speed stereoscopy of aurora. Annales Geophysicae, 34(1), 41-44. https://doi.org/10.5194/angeo-34-41-2016

Kataoka, R., Fukuda, Y., Miyoshi, Y., Miyahara, H., Itoya, S., Ebihara, Y., Hampton, D., Dahlgren, H., Whiter, D., Ivchenko, N. (2015). Compound auroral micromorphology: ground-based high-speed imaging. Earth, Planets and Space, 67(1), 23. https://doi.org/10.1186/s40623-015-0190-6 
Kataoka, R., Y. Miyoshi, D. Hampton, T. Ishii, and H. Kozako (2012), Pulsating aurora beyond the ultra-low-frequency range, J. Geophys. Res., 117, A08336, doi:10.1029/2012JA017987.

Katoh, Y. and Y. Omura (2007), Computer simulation of chorus wave generation in the Earth's inner magnetosphere, Geophys. Res. Lett., 34, L03102, doi:10.1029/2006GL028594.

Katoh, Y. and Y. Omura (2011), Amplitude dependence of frequency sweep rates of whistler mode chorus emissions, J. Geophys. Res., 116, A07201, doi:10.1029/2011JA016496.

Katoh, Y. and Y. Omura (2013), Effect of the background magnetic field inhomogeneity on generation processes of whistler-mode chorus and hiss-like broadband emissions, J. Geophys. Res. Space Physics, 118, 4189-4198, doi:10.1002/jgra.50395.

Katoh, Y. (2014), A simulation study of the propagation of whistler-mode chorus in the Earth's inner magnetosphere, Earth Planets Space, 66, 6, doi:10.1186/1880-5981-66-6.

Katoh, Y. and Y. Omura (2016), Electron hybrid code simulation of whistler-mode chorus generation with real parameters in the Earth's inner magnetosphere, Earth Planets Space, 68:192, doi:10.1186/s40623-016-0568-0.

Katoh, Y., Y. Omura, Y. Miyake, H. Usui, and H. Nakashima (2018), Dependence of generation of whistler-mode chorus emissions on the temperature anisotropy and density of energetic electrons in the Earth's inner magnetosphere, J. Geophys. Res. Space Physics, 123, doi: 10.1002/2017JA024801.

Kawamura, S., Hosokawa, K., Kurita, S., Oyama, S., Miyoshi, Y., Kasahara, Y., et al. (2019). Tracking the region of high correlation between pulsating aurora and chorus: Simultaneous observations with Arase satellite and ground-based all-sky imager in Russia. Journal of Geophysical Research: Space Physics, 124, 2769- 2778. https://doi.org/10.1029/2019JA026496

Kennel, C. F. and H. E. Petschek (1966), Limits on stably trapped particle fluxes, J. Geophys. Res. 71, 1, doi:10.1029/ JZ071i001p00001.

Kenward, D. R., Lessard, M. R., Fritz, B. A., Varney, R., Michell, R. G. and Hampton, D. (2019), Observations of ion upflow during pulsating aurora, submitted to Journal of Geophysical Research: Space Physics.

Khazanov, G. V., D. G. Sibeck, and E. Zesta (2017), Is diffuse aurora driven from above or below?, Geophysical Research Letters, pp. n/a-n/a, doi:10.1002/2016GL072063, 2016GL072063.

Kirkwood, S., Opgenoorth, H., \& Murphree, J. S. (1988). Ionospheric conductivities, electric fields and currents associated with auroral substorms measured by the EISCAT radar. Planetary and Space Science, 36(12), 13591380. https://doi.org/10.1016/0032-0633(88)90005-0

Knudsen, D. J., J. K. Burchill, T. G. Cameron, G. A. Enno, A. Howarth and A. W. Yau (2015), The CASSIOPE/e-POP Suprathermal Electron Imager (SEI), Space Science Reviews, 189, 1-4, (65).

Knudsen, D. J., Burchill, J. K., Buchert, S. C., Eriksson, A. I., Gill, R., Wahlund, J.-E., Åhlen, L., Smith, M., and Moffat, B. (2017), Thermal ion imagers and Langmuir probes in the Swarm electric field instruments, J. Geophys. Res. Space Physics, 122, 2655-2673, doi:10.1002/2016JA022571.

Kosch, M. J., Honary, F., del Pozo, C. F., Marple, S. R., \& Hagfors, T. (2001). High-resolution maps of the characteristic energy of precipitating auroral 
particles. Journal of Geophysical Research, 106(A12), 28925-28937. https://doi.org/10.1029/2001JA900107

Kurita, S., Y. Katoh, Y. Omura, V. Angelopoulos, C. M. Cully, O. Le Contel, and H. Misawa (2012), THEMIS observation of chorus elements without a gap at half the gyrofrequency, J. Geophys. Res., 117, A11223, doi:10.1029/2012JA018076.

Lanchester, B. S., M. Ashrafi, and N. Ivchenko (2009), Simultaneous imaging of aurora on small scale in OI (777.4 nm) and N2 1P to estimate energy and flux of precipitation, Ann. Geophys., 27, 2881-2891, doi:10.5194/angeo-27-28812009

Lessard, M. R. (2013). A Review of Pulsating Aurora. Auroral Phenomenology and Magnetospheric Processes: Earth and Other Planets, Geophys. Monogr. Ser., 197, 55-68. https://doi.org/10.1029/2011GM001187

Li, W. , Bortnik, J. , Nishimura, Y., Thorne, R. M. and Angelopoulos, V. (2013). The Origin of Pulsating Aurora: Modulated Whistler Mode Chorus Waves. In Auroral Phenomenology and Magnetospheric Processes: Earth And Other Planets (eds A. Keiling, E. Donovan, F. Bagenal and T. Karlsson). doi:10.1029/2011GM001164

Liang, J., B. Ni, E. Spanswick, M. Kubyshkina, E. F. Donovan, V. M. Uritsky, R. M. Thorne, and V. Angelopoulos (2011), Fast earthward flows, electron cyclotron harmonic waves, and diffuse auroras: Conjunctive observations and a synthesized scenario, Journal of Geophysical Research, 116, A12220, doi:10.1029/2011JA017094

Liang, J., E. Donovan, Y. Nishimura, B. Yang, E. Spanswick, K. Asamura, Sakanoi T., D. Evans, and R. Redmon (2015), Low-energy ion precipitation structures associated with pulsating auroral patches, J. Geophys. Res. Space Physics, 120, 5408-5431, doi:10.1002/ 2015JA021094.

Liang J., E. Donovan, B. Jackel, E. Spanswick, and M. Gillies (2016). On the 630nm red-line pulsating aurora: Red-line Emission Geospace Observatory observations and model simulations. Journal of Geophysical Research: Space Physics, 121(8):7988-8012. doi: 10.1002/2016JA022901. URL https://agupubs.onlinelibrary.wiley.com/doi/abs/10.1002/2016JA022901.

Liang, J., Donovan, E., Reimer, A., Hampton, D., Zou, S., \& Varney, R. (2018). Ionospheric electron heating associated with pulsating auroras: Joint optical and PFISR observations. Journal of Geophysical Research: Space Physics, 123, 4430-4456. https://doi.org/10.1029/ 2017JA025138

Liu, X., Chen, L., Gu, W., and Zhang, X.-J.(2018). Electron cyclotron harmonicwave instability by loss cone distribu-tion.Journal of Geophysical Research, 123, 9035-9044.https://doi.org/10.1029/2018JA025925

Lui, A. T. Y., Perreault, P., Akasofu, S. I., \& Anger, C. D. (1973). The diffuse aurora. Planetary and Space Science, 21(5), 857-857.

Lui, A. T. Y., Anger, C. D., Heikkila, W. J., \& Burrows, J. R. (1977). Simultaneous Observations of Particle Precipitations and Auroral. Journal of Geophysical Research, 82(16), 2210-2226.

Lui, A. T. Y., L. L. Cogger, A. Howarth, and A. W. Yau (2015), First satellite imaging of auroral pulsations by the Fast Auroral Imager on e-POP, Geophys. Res. Lett., 42, 6877-6882, doi:10.1002/2015GL065331.

Lyons, R. (1974). Electron diffusion driven by magnetospheric electrostatic waves. Journal of Geophysical Research, 79(4), 575-580. https://doi.org/10.1029/JA079i004p00575 
Maggs, J. E., \& Davis, T. N. (1968). Measurements of the thicknesses of auroral structures. Planetary and Space Science, 16(2), 205-209. https://doi.org/10.1016/0032-0633(68)90069-X

McEwen, D. J. and Duncan, C. N. (1981), A campaign to study pulsating auroras, Canadian Journal of Physics, 59 (8), 1029-1033, 10.1139/p81-135.

McEwen, D. J., Yee, E., Whalen, B. A., \& Yau, A. W. (1981). Electron energy measurements in pulsating auroras. Canadian Journal of Physics, 59(8), 1106-1115. https://doi.org/10.1139/p81-146

McKay, D., Paavilainen, T., Gustavsson, B., Kvammen, A., \& Partamies, N. (2019). Lumikot: Fast auroral transients during the growth phase of substorms. Geophysical Research Letters, 46, 7214- 7221. https://doi.org/10.1029/2019GL082985

McKay, D., Partamies, N., \& Vierinen, J. (2018). Pulsating aurora and cosmic noise absorption associated with growth-phase arcs. Annales Geophysicae, 36(1), 59-69. https://doi.org/10.5194/angeo-36-59-2018

Mende, S. B., Frey, H. U., Carlson, C. W., McFadden, J., Gérard, J., Hubert, B., ... Burch, J. L. (2002). IMAGE and FAST observations of substorm recovery phase aurora. Geophysical Research Letters, 29(12), 1602. https://doi.org/10.1029/2001GL013027

Mende, S. B., Harris, S. E., Frey, H. U., Angelopoulos, V., Russell, C. T., Donovan, E., Peticolas, L. M. (2008). The THEMIS Array of Ground-based Observatories for the Study of Auroral Substorms. Space Science Reviews, 141(1-4), 357-387. https://doi.org/10.1007/s11214-008-9380-x

Michell, R. G., and M. Samara (2015), Ground magnetic field fluctuations associated with pulsating aurora, Journal of Geophysical Research (Space Physics), 120, 9192-9201, doi: 10.1002/2015JA021252.

Michell, R. G., M. G. McHarg, M. Samara, and D. L. Hampton (2012), Spectral analysis of flickering aurora, J. Geophys. Res., 117, A03321, doi:10.1029/2011JA016703.

Michell, R. G., T. Grydeland, and M. Samara (2014), Characteristics of Poker Flat Incoherent Scatter Radar (PFISR) naturally enhanced ionacoustic lines (NEIALs) in relation to auroral forms, Annales Geophysicae, 32, 1333-1347, doi: 10.5194/angeo-32-1333-2014.

Miyoshi, Y., Y. Katoh, T. Nishiyama, T. Sakanoi, K. Asamura, and M. Hirahara (2010), Time of flight analysis of pulsating aurora electrons, considering wave-particle interactions with propagating whistler mode waves, J. Geophys. Res., 115, A10312, doi:10.1029/2009JA015127.

Miyoshi, Y., S. Oyama, S. Saito, S. Kurita, H. Fujiwara, R. Kataoka, Y. Ebihara, C. Kletzing, G. Reeves, O. Santolik, M. Clilverd, C. J. Rodger, E. Turunen, and F. Tsuchiya (2015a), Energetic electron precipitation associated with pulsating aurora: EISCAT and Van Allen Probe observations, J. Geophys. Res., 120, doi:10.1002/2014JA020690.

Miyoshi, Y., S. Saito, K. Seki, T. Nishiyama, R. Kataoka, K. Asamura, Y. Katoh, Y. Ebihara, T. Sakanoi, M. Hirahara, S. Oyama, S. Kurita, and O. Santolik (2015b), Relation between fine structure of energy spectra for pulsating aurora electrons and frequency spectra of whistler mode chorus waves, J. Geophys. Res., 120, doi:10.1002/2015JA021562.

Motoba, T., Y. Ebihara, A. Kadokura,M. J. Engebretson, M. R. Lessard, A. T. Weatherwax, and A. J. Gerrard (2017), Fast-moving diffuse auroral patches: A new aspect of daytime Pc3 auroral pulsations, J. Geophys. Res. Space Physics,122, 1542-1554, doi:10.1002/2016JA023285. 
Nakamura, R., and Oguti, T. (1987), Drifts of auroral structures and magnetospheric electric fields, J. Geophys. Res., 92( A10), 11241- 11247, doi:10.1029/JA092iA10p11241.

Newell, P. T., Feldstein, Y. I., Galperin, Y. I., \& Meng, C.-I. (1996). Morphology of nightside precipitation. Journal of Geophysical Research, 101 (A5), 1073710748. doi: 10.1029/95JA03516

Ni, B., Thorne, R. M., Shprits, Y. Y., \& Bortnik, J. (2008). Resonant scattering of plasma sheet electrons by whistler-mode chorus: Contribution to diffuse auroral precipitation. Geophysical Research Letters, 35, L11106. https://doi.org/10.1029/2008GL034032

Ni, B., R. Thorne, J. Liang, V. Angelopoulos, C. Cully, W. Li, X. Zhang, M. Hartinger, O. Le Contel, and A. Roux (2011), Global distribution of electrostatic electron cyclotron harmonic waves observed on THEMIS, Geophysical Research Letters, 38, L17105, doi:10.1029/2011GL048793

Ni, B., J. Liang, R. M. Thorne, V. Angelopoulos, R. B. Horne, M. Kubyshkina, E. Spanswick, E. F. Donovan, and D. Lummerzheim (2012), Efficient diffuse auroral electron scattering by electrostatic electron cyclotron harmonic waves in the outer magnetosphere: A detailed case study, Journal of Geophysical Research, 117, A01218, doi:10.1029/2011JA017095

Ni, B., X. Gu, S. Fu, Z. Xiang, and Y. Lou (2017), A statistical survey of electrostatic electron cyclotron harmonic waves based on THEMIS FFF wave data, Journal of Geophysical Research: Space Physics, 122, 3342-3353, doi:10.1002/2016JA023433

Ni, B., Thorne, R. M., Zhang, X., Bortnik, J., Pu, Z., Xie, L., Hu, Z.-J., Han, D., Shi, R., Zhou, C., \& Gu, X. (2016). Origins of the Earth's diffuse auroral precipitation. Space Science Reviews, 200(1-4), 205-259. https://doi.org/10.1007/s11214-016-0234-7

Nicolls, M. J., \& Heinselman, C. J. (2007). Three-dimensional measurements of traveling ionospheric disturbances with the Poker Flat Incoherent Scatter Radar. Geophysical Research Letters, 34(21), L21104. https://doi.org/10.1029/2007GL031506

Nishi, K., Shiokawa, K., \& Spence, H. (2018). Magnetospheric Source Region of Auroral Finger-like Structures Observed by the RBSP-A Satellite. Journal of Geophysical Research: Space Physics, 123(9), 7513-7522. https://doi.org/10.1029/2018JA025480

Nishiyama, T., T. Sakanoi, Y. Miyoshi, Y. Katoh, K. Asamura, S. Okano, and M. Hirahara (2011), The source region and its characteristic of pulsating aurora based on the Reimei observations, J. Geophys. Res., 116, A03226, doi:10.1029/2010JA015507.

Nishimura, Y., et al. (2010), Identifying the Driver of Pulsating Aurora, Science, $330,81$.

Nishimura, Y., et al. (2011), Estimation of magnetic field mapping accuracy using the pulsating aurora-chorus connection, Geophys. Res. Lett., 38, L14110, doi:10.1029/2011GL048281.

Nishimura, Y., Bortnik, J., Li, W., Thorne, R. M., Ni, B., Lyons, L. R., ... Auster, U. (2013). Structures of dayside whistler-mode waves deduced from conjugate diffuse aurora. Journal of Geophysical Research: Space Physics, 118(2), 664-673. https://doi.org/10.1029/2012JA018242

Nishimura, Y., Bortnik, J., Li, W., Liang, J., Thorne, R. M., Angelopoulos, V., Le Contel, O., Auster, U., and Bonnell, J. W. (2015), Chorus intensity modulation 
driven by time-varying field-aligned low-energy plasma, J. Geophys. Res. Space Physics, 120, 7433- 7446, doi:10.1002/2015JA021330.

Nishimura, Y., Bortnik, J., Li, W., Angelopoulos, V., Donovan, E. F., \& Spanswick, E. L. (2018). Comment on "Pulsating auroras produced by interactions of electrons and time domain structures" by Mozer et al. Journal of Geophysical Research: Space Physics, 123, 2064-2070. https://doi.org/10.1002/2017JA024844

Nishiyama T., T. Sakanoi, Y. Miyoshi, R. Kataoka, D. Hampton, Y. Katoh, K. Asamura, and S. Okano (2012). Fine scale structures of pulsating au roras in the early recovery phase of substorm using ground-based EMCCD camera. Journal of Geophysical Research: Space Physics, 117(A10). doi: 10.1029/2012JA017921.

URL https://agupubs.onlinelibrary.wiley.com/doi/abs/10.1029/2012JA017921.

Nishiyama, T., T. Sakanoi, Y. Miyoshi, Y. Katoh, K. Asamura, S. Okano, and M. Hirahara (2011), The source region and its characteristic of pulsating aurora based on the Reimei observations, Journal of Geophysical Research (Space Physics), 116, A03226, doi:10.1029/2010JA015507.

Nishiyama T., T. Sakanoi, Y. Miyoshi, D. L. Hampton, Y. Katoh, R. Kataoka, and S. Okano (2014). Multiscale temporal variations of pulsat- ing auroras: On-off pulsation and a few $\mathrm{Hz}$ modulation. Journal of Geophysical Research: Space Physics, 119(5):35143527. doi:10.1002/2014JA019818. https://agupubs.onlinelibrary.wiley.com/doi/abs/10.1002/2014JA019818.

Nishiyama T., Y. Miyoshi, Y. Katoh, T. Sakanoi, R. Kataoka, and S. Okano (2016). Substructures with luminosity modulation and horizontal oscillation in pulsating patch: Principal component analysis application to pulsating aurora. Journal of Geophysical Research: Space Physics, 121(3):2360-2373. doi: 10.1002/2015JA022288. URL https://agupubs.onlinelibrary.wiley.com/doi/abs/10.1002/2015JA022288.

O’Brien, B. J. (1964), High-latitude geophysical studies with satellite injun 3: 3. precipitation of electrons into the at- mosphere, Journal of Geophysical Research, 69(1), 13-43, doi:10.1029/JZ069i001p00013.

Oguti, T., Kokubun, S., Hayashi, K., Tsuruda, K., Machida, S., Kitamura, T., Saka, O., and Watanabe, T. (1981a): Statistics of pul- sating auroras on the basis of all- $\quad$ sky TV data from five sta- tions. I - Occurrence frequency, Can. J. Phys., 59, 1150-1157, https://doi.org/10.1139/p81-152.

Oguti, T., S. Kokubun, K. Hayashi, K. Tsuruda, S. Machida, T. Kitamura, O. Saka, and T. Watanabe (1981b), Latitudinally propagating on-off switching aurorae and associated geomagnetic pulsations: A case study of an event of February 20, 1980, Can. J. Phys., 59, 1131-1136.

Oguti, T., \& Hayashi, K. (1984). Multiple correlation between auroral and magnetic pulsations: 2. Determination of electric currents and electric fields around a pulsating auroral patch. Journal of Geophysical Research: Space Physics, 89(A9), 7467-7481. https://doi.org/10.1029/JA089iA09p07467

Omura, Y., Y. Katoh, D. Summers (2008), Theory and simulation of the generation of whistler-mode chorus, J. Geophys. Res., 113, A04223, doi:10.1029/2007JA012622.

Omura, Y., M. Hikishima, Y. Katoh, D. Summers, and S. Yagitani (2009), Nonlinear mechanisms of lower band and upper band VLF chorus emissions in the magnetosphere, J. Geophys. Res., 114, A07217, doi:10.1029/2009JA014206. 
Omura, Y., and D. Nunn (2011), Triggering process of whistler-mode chorus emissions in the magnetosphere, J. Geophys. Res., 116, A05205, doi:10.1029/2010JA016280.

Oyama, S., Shiokawa, K., Miyoshi, Y., Hosokawa, K., Watkins, B. J., Kurihara, J., Fallen, C. T. (2016). Lower thermospheric wind variations in auroral patches during the substorm recovery phase. Journal of Geophysical Research: Space Physics, 121(4), 3564-3577. https://doi.org/10.1002/2015JA022129

Oyama, S., Shiokawa, K., Kurihara, J., Tsuda, T. T., Nozawa, S., Ogawa, Y., Watkins, B. J. (2010). Lower-thermospheric wind fluctuations measured with an FPI during pulsating aurora at Troms $\emptyset$, Norway. Annales Geophysicae, 28(10), 1847-1857. https://doi.org/10.5194/angeo-28-1847-2010

Oyama, S., A. Kero, C. J. Rodger, M. A. Clilverd, Y. Miyoshi, N. Paratamies, E. Turunen, T. Raita, P. T. Verronen, and S. Saito (2017), Energetic electron precipitation and auroral morphology at the substorm recovery phase, $J$. Geophys. Res., 122, 6508-6527, doi:10.1002/2016JA023484.

Ozaki, M., et al. (2015), A direct link between chorus emissions and pulsating aurora on timescales from milliseconds to minutes: A case study at subauroral latitudes, J. Geophys. Res. Space Physics, 120, 9617- 9631, doi:10.1002/2015JA021381.

Ozaki, M., K. Shiokawa, Y. Miyoshi, K. Hosokawa, S. Oyama, S. Yagitani, Y. Kasahara, Y. Kasaba, S. Matsuda, R. Kataoka, Y. Ebihara, Y. Ogawa, Y. Otsuka, S. Kurita, R. C. Moore, Y.-M. Tanaka, Nos, T. Nagatsuma, M. Connors, N. Nishitani, Y. Katoh, M. Hikishima, A. Kumamoto, F. Tsuchiya, A. Kadokura, T. Nishiyama, T. Inoue, K. Imamura, A. Matsuoka, and I. Shinohara (2018). Microscopic observations of pulsating aurora associated with chorus element structures: Coordinated arase satellite-pwing observations. Geophysical Research Letters, 45(22):12,125-12,134. doi: 10.1029/2018GL079812.

URL https://agupubs.onlinelibrary.wiley.com/doi/abs/10.1029/2018GL079812.

Ozaki, M., et al. (2019), Visualization of rapid electron precipitation via chorus element wave-particle interactions, NATURE COMMUNICATIONS, 10:257, 10:257, https://doi.org/10.1038/s41467-018-07996-z

Partamies N., D. Whiter, A. Kadokura, K. Kauristie, H. Nesse Tyssøy, S. Massetti, P. Stauning, and T. Raita (2017a). Occurrence and average behavior of pulsating aurora. Journal of Geophysical Research (Space Physics), 122:5606-5618. doi: 10.1002/2017JA024039.

Partamies, N., J. M. Weygand, and L. Juusola (2017b). Statistical study of auroral omega bands. Annales Geophysicae, 35:1069-1083. doi: 10.5194/angeo-351069-2017.

Partamies, N., Bolmgren, K., Heino, E., Ivchenko, N., Borovsky, J. E., Dahlgren, H. (2019). Patch size evolution during pulsating aurora. Journal of Geophysical Research: Space Physics, 124, 4725- 4738. https://doi.org/10.1029/2018JA026423

Peticolas, L. M., Hallinan, T. J., Stenbaek-Nielsen, H. C., Bonnell, J. W., \& Carlson, C. W. (2002). A study of black aurora from aircraft-based optical observations and plasma measurements on FAST. Journal of Geophysical Research: Space Physics, 107(A8), SMP 30-1-SMP 30-11. https://doi.org/10.1029/2001JA900157

Rees, M. H. (1968), Conjugate effects of atmospherically scattered auroral electrons, Radio Science, 3(7), 645-649, doi: 10.1002/rds196837645.

Robinson, R. (2004). New techniques and results from incoherent scatter radars. 
URSI Radio Science Bulletin, 2004(311), 79-94. https://doi.org/10.23919/URSIRSB.2004.7909637

Roeder, J. L., and H. C. Koons (1989), A survey of electron cyclotron waves in the magnetosphere and the diffuse auroral electron precipitation, Journal of Geophysical Research, 94, 2529-2541, doi:10.1029/JA094iA03p02529.

Royrvik, O., and T. N. Davis (1977), Pulsating aurora: Local and global morphology, J. Geophys. Res., 82(29), 4720-4740.

Saito, S., Y. Miyoshi, and K. Seki (2012), Relativistic electron microbursts associated with whistler chorus rising tone elements: GEMSIS-RBW simulations, J. Geophys. Res., 117, A10206, doi:10.1029/2012JA018020.

Samara, M., and R. G. Michell (2010), Ground-based observations of diffuse auroral frequencies in the context of whistler mode chorus, J. Geophys. Res., 115, doi: doi:10.1029/2009JA014852.

Samara, M., Michell, R. G., Asamura, K., Hirahara, M., Hampton, D. L., \& Stenbaek-Nielsen, H. C. (2010). Ground-based observations of diffuse auroral structures in conjunction with Reimei measurements, Annales Geophysicae, 28(3), 873-881. https://doi.org/10.5194/angeo-28-873-2010

Samara, M., R. G. Michell, and R. J. Redmon (2015), Low- altitude satellite measurements of pulsating auroral electrons, Journal of Geophysical Research (Space Physics), 120, 8111-8124, doi:10.1002/2015JA021292.

Samara, M., R. G. Michell, and G. V. Khazanov (2017), First optical observations of interhemispheric electron reflections within pulsating aurora, Geophys. Res. Lett., , 44, 2618- 2623, doi:10.1002/2017GL072794.

Sandahl, I. (1985), Pitch angle scattering and particle precipitation in a pulsating aurora: An experimental study, KGI Rept. 185, Kiruna Geophys. Inst., Kiruna, Sweden

Sandahl, I., L. Eliasson, and R. Lundin (1980), Rocket observations of precipitating electrons over a pulsating aurora, Geophys. Res. Lett., 7, 309312, doi:10.1029/GL007i005p00309.

Sangalli, L., N. Partamies, M. Syrjäsuo, C.-F. Enell, K. Kauristie \& S. Mäkinen (2011): Performance study of the new EMCCD-based all-sky cameras for auroral imaging, International Journal of Remote Sensing, 32:11, 2987-3003. http://dx.doi.org/10.1080/01431161.2010.541505

Santolik, O., D. A. Gurnett, J. S. Pickett, M. Parrot, and N. Cornilleau-Wehrlin (2003), Spatio-temporal structure of storm-time chorus, J. Geophys. Res., 108(A7), 1278, doi:10.1029/2002JA009791.

Santolik, O., Macusova, E., Kolmasova, I., Cornilleau-Wehrlin, N., and de Conchy, Y.(2014). Propagation of lower-band whistler-mode waves in the outer van allen 346 belt: Systematic analysis of 11 years of multi-component data from the cluster, Geophys. Res. Lett., 41, 27292737,https://doi.org/10.1002/2014GL059815.

Sato, K., M. Tsutsumi, T. Sato, T. Nakamura, A. Saito, Y. Tomikawa, K. Nishimura, M. Kohma, H. Yamagishi, T. Yamanouchi (2014), Program of the Antarctic Syowa MST/IS radar (PANSY), Journal of Atmospheric and SolarTerrestrial Physics Volume 118, Part A, Pages 2-15, https://doi.org/10.1016/j.jastp.2013.08.022

Sato, N., A. S. Yukimatu, Y. Tanaka, and T. Hori (2017). Morphologies of omega band auroras. Earth, Planets, and Space, 69:103. doi: 10.1186/s40623-0170688-1.

Sato, N., A. Kadokura, Y. Tanaka, T. Nishiyama, T. Hori, and A. S. Yukimatu (2015). Omega band pulsating auroras observed onboard THEMIS spacecraft 
and on the ground. Journal of Geophysical Research (Space Physics), 120:5524-5544. doi: 10.1002/2015JA021382.

Saito, S., Y. Miyoshi, and K. Seki (2012), Relativistic electron microbursts associated with whistler chorus rising tone elements: GEMSIS-RBW simulations, J. Geophys. Res., 117, A10206, doi:10.1029/2012JA018020.

Scourfield, M. W. J., W. F. Innes, N. R. Parsons (1972), Spatial coherency in pulsating aurora, Planet. Space Sci., 20, 1843-1848.

Semeter, J., Mendillo, M., \& Baumgardner, J. (1999). Multispectral tomographic imaging of the midlatitude aurora. Journal of Geophysical Research: Space Physics, 104(A11), 24565-24585. https://doi.org/10.1029/1999JA900305

Semeter, J., \& Kamalabadi, F. (2005). Determination of primary electron spectra from incoherent scatter radar measurements of the auroral e region. Radio Science, 40(2), 1-17. https://doi.org/10.1029/2004RS003042

Sergeev, V. A., Sazhina, E. M., Tsyganenko, N. A., Lundblad, J. A., \& Soraas, F. (1983). Pitch-angle scattering of energetic protons in the magnetotail current sheet as the dominant source of their isotropic precipitation into the nightside ionosphere. Planetary and Space Science, 31 (10), 1147-1155. doi:

10.1016/0032-0633(83)90103-4

Sergeev, V. A., Nishimura, Y., Kubyshkina, M., Angelopoulos, V., Nakamura, R.,

\& Singer, H. (2012). Magnetospheric location of the equatorward prebreakup arc. Journal of Geophysical Research: Space Physics, 117(A1). doi: 10.1029/2011JA017154

Sergienko, T., Sandahl, I., Gustavsson, B., Andersson, L., Brändström, U., \& Steen, and $\AA$. (2008). A study of fine structure of diffuse aurora with ALISFAST measurements (Vol. 26). Retrieved from www.anngeophys.net/26/3185/2008/

Shiokawa, K., A. Nakajima, A. Ieda, K. Sakaguchi, R. Nomura, T. Aslaksen, M. Greffen, and E. Donovan (2009). Rayleigh-Taylor type instability in auroral patches. Journal of Geophysical Research: Space Physics, 115(A2). doi: 10.1029/2009JA014273.

Shiokawa, K., et al. (2014), Auroral fragmentation into patches, J. Geophys. Res. Space Physics, 119, 8249- 8261, doi:10.1002/2014JA020050.

Shiokawa, K., Katoh, Y., Hamaguchi, Y., Yamamoto, Y., Adachi, et al. (2017). Ground-based instruments of the pwing project to investigate dynamics of the inner magnetosphere at subauroral latitudes as a part of the erg-ground coordinated observation network. Earth, Planets and Space, 69(1), 160. doi:10.1186/s40623-017-0745-9

Sivadas, N., Semeter, J., Nishimura, Y., \& Kero, A. (2017). Simultaneous Measurements of Substorm-Related Electron Energization in the Ionosphere and the Plasma Sheet. Journal of Geophysical Research: Space Physics, 122(10), 10,528-10,547. https://doi.org/10.1002/2017JA023995

Sivadas, N., Semeter, J., Nishimura, Y., \& Mrak, S. (2019). Optical Signatures of the Outer Radiation Belt Boundary. Geophysical Research Letters, 46. https://doi.org/10.1029/2019GL083908

Smith, M. J., D. A. Bryant, and T. Edwards (1980), Pulsations in auroral electrons and positive ions, J. Atmos. Terr. Phys., 42, 167.

Solomon, S. C., Hays, P. B., \& Abreu, V. J. (1984). Tomographic inversion of satellite photometry. Applied Optics, 23(19), 3409. https://doi.org/10.1364/AO.23.003409

Sørensen, T., Bjordal, J., Trefall, H., Kvifte, G. J., \& Pettersen, H. (1973). 
Correlation between pulsations in auroral luminosity variations and X-rays. Journal of Atmospheric and Terrestrial Physics, 35(5), 961-969. https://doi.org/10.1016/0021-9169(73)90075-5

Spanswick, E, E Donovan and G Baker (2005), Pc5 modulation of high energy electron precipitation: particle interaction regions and scattering efficiency, Ann. Geophys., 23, 1533-1542.

Stenbaek-Nielsen, H. C. (1980), Pulsating aurora - The importance of the ionosphere, Geophys.Res. Lett., 7, 353-356, doi:10.1029/GL007i005p00353.

Stenbaek-Nielsen, H. C., and T. J. Hallinan (1979), Pulsat- ing auroras - Evidence for noncollisional thermalization of precipitating electrons, J. Geophys. Res., 84, 3257-3271, doi:10.1029/JA084iA07p03257.

Stenbaek-Nielsen, H. C., Hallinan, T. J., \& Peticolas, L. (1999). Why do auroras look the way they do? Eos, Transactions American Geophysical Union, 80(17), 193. https://doi.org/10.1029/99EO00138

Stormer, C., The Polar Aurora, Oxford at the Clarendon Press, Great Britain, 1955.

Strangeway, R. J., R. E. Ergun, Y.-J. Su, C. W. Carlson, and R. C. Elphic (2005), Factors controlling ionospheric outflows as observed at intermediate altitudes, J. Geophys. Res., 110, A03221, doi:10.1029/2004JA010829.

Summers, D., R. Tang, Y. Omura, and D.-H. Lee (2013), Parameter spaces for linear and nonlinear whistler-mode waves, Phys. Plasmas 20, 072110, doi:10.1063/1.4816022.

Takahashi, T., et al. (2017), Depletion of mesospheric sodium during extended period of pulsating aurora, J. Geophys. Res. Space Physics,122, 1212-1220, doi:10.1002/2016JA023472.

Tanaka, Y.-M., Aso, T., Gustavsson, B., Tanabe, K., Ogawa, Y., Kadokura, A., Miyaoka, H., Sergienko, T., Brändström, U., and Sandahl, I. (2011): Feasibility study on Generalized-Aurora Computed Tomography, Ann. Geophys., 29, 551-562, https://doi.org/10.5194/angeo-29-551-2011.

Tanaka, Y., Y. Ogawa, A. Kadokura, N. Partamies, D. Whiter, C.-F. Enell, U. Brändström, T. Sergienko, B. Gustavsson, A. Kozlovsky, H. Miyaoka, and A. Yoshikawa (2015). Eastward-expanding auroral surges observed in the post-midnight sector during a multiple-onset substorm. Earth, Planets and Space, 67(1):182, Nov 2015. ISSN 1880-5981. doi: 10.1186/s40623-0150350-8.

Thorne, R. M., B. Ni, X. Tao, R. B. Horne, and N. P. Meredith (2010), Scattering by chorus waves as the dominant cause of diffuse auroral precipitation, Nature, 467, 943-946, doi:10.1038/nature09467.

Thomas, R. W., and H. C. Stenbaek-Nielsen (1981), Recurrent propagating auroral forms in pulsating auroras, J. Atmos. Terr. Phys., 43, 243.

Tsuda, T. T., et al. (2013), Decrease in sodium density observed during auroral particle precipitation over Troms $\varnothing$, Norway, Geophys. Res. Lett., 40, 44864490, doi:10.1002/grl.50897.

Tsuruda, K., Machida, S., Oguti, T., Kokubun, S., Hayashi, K., Kitamura, T., Saka, O., \& Watanabe, T. (1981). Correlations between the very low frequency chorus and pulsating aurora observed by low-light-level television at $\mathrm{L}=4.4$. Canadian Journal of Physics, 59(8), 1042-1048. https://doi.org/10.1139/p81137

Turunen, E., A. Kero, P. T. Verronen, Y. Miyoshi, S-I. Oyama, and S. Saito (2016), Mesospheric ozone destruction by high-energy electron precipitation associated with pulsating aurora, J. Geophys. Res., 121, doi:10.1002/2016JD025015. 
Unick, C. W., Donovan, E., Connors, M., \& Jackel, B. (2017). A dedicated H-beta meridian scanning photometer for proton aurora measurement. Journal of Geophysical Research: Space Physics, 122(1), 753-764. https://doi.org/10.1002/2016JA022630

Watanabe, M., Kadokura, A., Sato, N., and Saemundsson, T. (2007), Absence of geomagnetic conjugacy in pulsating auroras, Geophys. Res. Lett., 34, L15107, doi:10.1029/2007GL030469.

Wahlund, J.-E., H. J. Opgenoorth, I. Haggstrom, K. J. Winser, and G. O. L. Jones (1992), EISCAT observations of topside ionospheric ion outflows during auroral activity - Revisited, J. Geophys. Res., 97, 3019-3037.

Weygand, J. M., M. G. Kivelson, H. U. Frey, J. V. Rodriguez, V. Angelopoulos, R. Redmon, J. Barker-Ream, Grocott, and O. Amm (2015). An interpretation of spacecraft and ground based observations of multiple omega band events. Journal of Atmospheric and Solar-Terrestrial Physics, 133:185-204. doi: 10.1016/j.jastp.2015.08.014.

Whiter, D. K., Gustavsson, B., Partamies, N., and Sangalli, L. (2013): A new automatic method for estimating the peak auroral emission height from allsky camera images, Geosci. Instrum. Method. Data Syst., 2, 131-144, https://doi.org/10.5194/gi-2-131-2013.

Wilson, C. R., Olson, J. V., \& Stenbaek-Nielsen, H. C. (2005). High trace-velocity infrasound from pulsating auroras at Fairbanks, Alaska. Geophysical Research Letters, 32(14), n/a-n/a. https://doi.org/10.1029/2005GL023188

Yang, B., E. Donovan, J. Liang, J. M. Ruohoniemi, and E. Spanswick (2015). Using patchy pulsating aurora to remote sense magnetospheric convection. Geophysical Research Letters, 42:5083-5089. doi: 10.1002/2015GL064700.

Wu, Q. and Rosenberg, T. J. (1992), High Latitude Pulsating Aurora Revisited, Geophys. Res. Lett., VOL. 19, NO. 1, PAGES 69-72

Yamamoto, T. (1988), On the temporal fluctuations of pulsating auroral luminosity, J. Geophys. Res., 93(A2), 897- 911, doi:10.1029/JA093iA02p00897.

Yamamoto, T., and Oguti, T. (1982), Recurrent fast motions of pulsating auroral patches: 1. A case study on optical and quantitative characteristics during a slightly active period, J. Geophys. Res., 87( A9), 7603- 7614, doi:10.1029/JA087iA09p07603.

Yang, B., E. Donovan, J. Liang, and E. Spanswick (2017). A statistical study of the motion of pulsating aurora patches: using the THEMIS All-Sky Imager. Annales Geophysicae, 35:217-225. doi: 10.5194/angeo-35-217-2017.

Yang, B., Spanswick, E., Liang, J., Grono, E., \& Donovan, E. (2019). Responses of different types of pulsating aurora in cosmic noise absorption.

Geophysical Research Letters, 46, 5717- 5724. https://doi.org/10.1029/2019GL083289

Zhang, Y., Paxton, L. J., Morrison, D., Lui, A. T. Y., Kil, H., Wolven, B., ... Christensen, A. B. (2005). Undulations on the equatorward edge of the diffuse proton aurora: TIMED/GUVI observations. Journal of Geophysical Research: Space Physics, 110(A8). https://doi.org/10.1029/2004JA010668

Zhang, X., Angelopoulos, V., Ni, B., \& Thorne, R. M. (2015). Predominance of ECH wave contribution to diffuse aurora in Earth's outermagnetosphere.J. Geophys. Res.,120, 295-309. https://doi.org/10.1002/2014JA020455

Zhou, Q., F. Xiao, C. Yang, S. Liu,Y.He,D.N.Baker,H.E.Spence,G. D. Reeves, and H. O. Funsten (2017), Generation of lower and upper bandsof electrostatic 
electron cyclotronharmonic waves in the Van Allenradiation belts, Geophys.

Res. Lett.,44, 5251-5258, doi:10.1002/2017GL073051. 